\title{
Turbulent Aeroheating Testing of Mars Science Laboratory Entry Vehicle in Perfect-Gas Nitrogen
}

\author{
Brian R. Hollis* \\ NASA Langley Research Center, Hampton, VA, 23681 \\ Arnold S. Collier ${ }^{\dagger}$ \\ AEDC White Oak, Silver Spring, MD 20901
}

\begin{abstract}
An experimental investigation of turbulent aeroheating on the Mars Science Laboratory entry vehicle heat shield has been conducted in the Arnold Engineering Development Center Hypervelocity Wind Tunnel No. 9. Testing was performed on a 6-in. (0.1524 m) diameter MSL model in pure $\mathrm{N}_{2}$ gas in the tunnel's Mach 8 and Mach 10 nozzles at free stream Reynolds numbers of $4.1 \times 10^{6} / \mathrm{ft}$ to $49 \times 10^{6} / \mathrm{ft}\left(1.3 \times 10^{7} / \mathrm{m}\right.$ to $\left.16 \times 10^{7} / \mathrm{m}\right)$ and $1.2 \times 10^{6} / \mathrm{ft}$ to $19 \times 10^{6} /$ ft $\left(0.39 \times 10^{7} / \mathrm{m}\right.$ to $\left.62 \times 10^{7} / \mathrm{m}\right)$, respectively. These conditions were sufficient to span the regime of boundary-layer flow from completely laminar to fully-developed turbulent flow over the entire forebody. A supporting aeroheating test was also conducted in the Langley Research Center 20-Inch Mach 6 Air Tunnel at free stream Reynolds number of $1 \times 10^{6} / \mathrm{ft}$ to $7 \times 10^{6} / \mathrm{ft}\left(0.36 \times 10^{7} / \mathrm{m}\right.$ to $\left.2.2 \times 10^{7} / \mathrm{m}\right)$ in order to help corroborate the Tunnel 9 results. A complementary computational fluid dynamics study was conducted in parallel to the wind tunnel testing. Laminar and turbulent predictions were generated for all wind tunnel test conditions and comparisons were performed with the data for the purpose of helping to define uncertainty margins on predictions for aeroheating environments during entry into the Martian atmosphere. Data from both wind tunnel tests and comparisons with the predictions are presented herein. It was concluded from these comparisons that for perfect-gas conditions, the computational tools could predict fully-laminar or fully-turbulent heating conditions to within $\pm \mathbf{1 0} \%$ of the experimental data.
\end{abstract}

\section{Nomenclature}

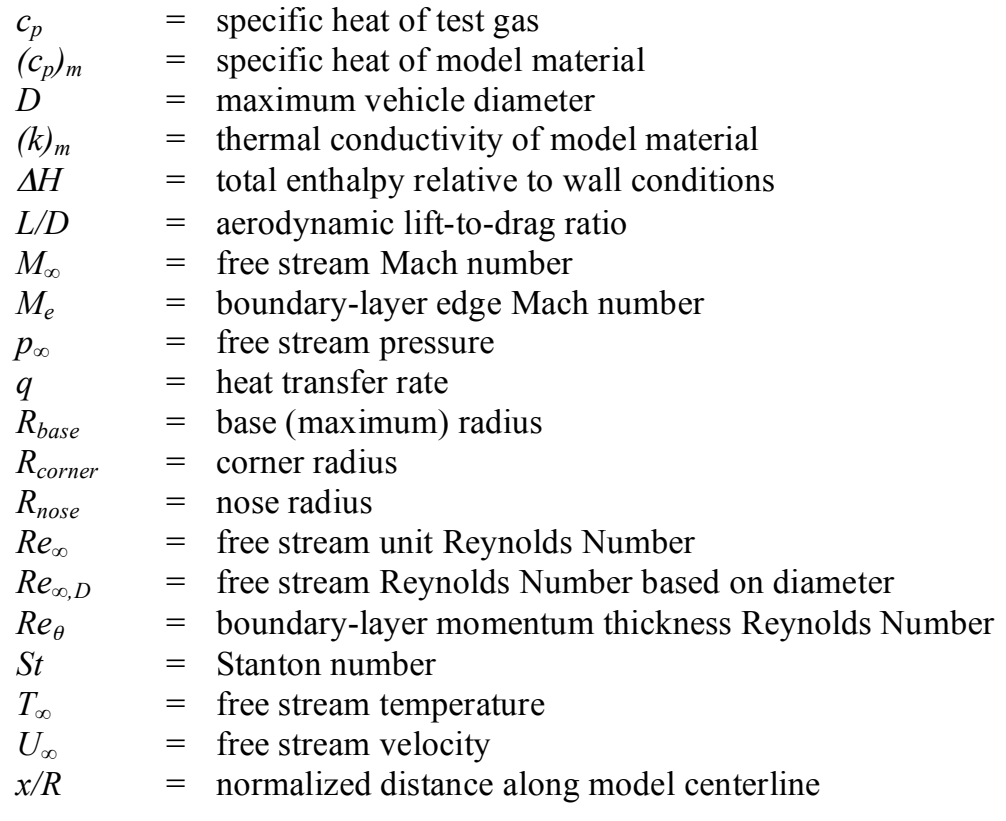

\footnotetext{
* Aerospace Engineer, Aerothermodynamics Branch, AIAA Senior Member

${ }^{\dagger}$ Project Engineer
} 


$\begin{array}{ll}\alpha & =\text { angle of attack } \\ \theta & =\text { boundary-layer momentum thickness } \\ \theta_{F} & =\text { forebody cone half-angle } \\ \theta_{a f t 1} & =1 \text { st aftbody cone half-angle } \\ \theta_{a f t 2} & =\text { nd aftbody cone half-angle } \\ (\rho)_{m} & =\text { density of model material } \\ \rho_{\infty} & =\text { free stream density } \\ \mu_{\infty} & =\text { free stream viscosity }\end{array}$

\section{Background}

The Mars Science Laboratory (MSL) mission ${ }^{1,2}$, which is scheduled to be launched in 2009, will perform the first precision landing of a large $(>3000 \mathrm{~kg})$ scientific payload on the surface of Mars in 2010 . While the basic vehicle configuration, a 70-deg sphere-cone forebody with a conic or biconic aftbody, will be similar to those of previous Mars missions such as Viking, Pathfinder or Mars Exploration Rover (MER), the MSL design is both larger and heavier than previous designs (Table 1). To accomplish a precision landing, the vehicle will be required to fly a controlled lifting trajectory; current designs call for a lift-to-drag ratio (L/D) of 0.24 , which will be generated by flying at an angle-of-attack of $-16 \mathrm{deg}$. As a result of its high ballistic coefficient, MSL will experience heating levels higher than any of the previous missions, and furthermore, because of the high angle-of-attack (for a blunt body) flight requirement, the flow over the leeside of the forebody is expected to become turbulent early in the trajectory, which will substantially augment both the heating rates and loads above the laminar levels ${ }^{3}$.

Table 1. Comparison of Mars Entry Vehicles

\begin{tabular}{|c|c|c|c|c|c|}
\hline & Viking $1 \& 2$ & Pathfinder & MER A \& B & Phoenix & MSL \\
\hline Configuration & & & & & \\
\hline Diameter, $\mathrm{m}$ & 3.5 & 2.65 & 2.65 & 2.65 & 4.5 \\
\hline Entry Mass, kg & 930 & 585 & 840 & 602 & $>3000$ \\
\hline Landed Mass, $\mathrm{kg}$ & 603 & 360 & 539 & 364 & $>1700$ \\
\hline Relative Entry Vel., km/s & $4.5 / 4.42$ & 7.6 & 5.5 & 5.9 & $>5.5$ \\
\hline Relative Entry Angle, deg & -17.6 & -13.8 & -11.5 & -13 & -15.2 \\
\hline Ballistic Coefficient, $\mathrm{kg} / \mathrm{m}^{2}$ & 63.7 & 62.3 & 89.8 & 65 & $>140$ \\
\hline Turbulent at Peak Heating? & No & No & No & No & Yes \\
\hline Peak Heat Flux, W/cm ${ }^{2}$ & 24 & 115 & 54 & 56 & $>200$ \\
\hline Hypersonic $\alpha$, deg & -11.2 & 0 & 0 & 0 & -15.5 \\
\hline Hypersonic L/D & 0.18 & 0 & 0 & 0 & 0.24 \\
\hline
\end{tabular}

Because there are relatively little data on the turbulent heating of very large-angle blunt cones such as the MSL entry vehicle, an extensive test program has been conducted to obtain data with which the accuracy of Computational Fluid Dynamics (CFD) tools used to predict flight environments can be compared. To-date, tests have been performed ${ }^{4-7}$ in the NASA Langley Research Center 20-Inch Mach 6 Air Tunnel (heat-shield penetration effects, perfect-gas environments, transition onset), the Calspan University of Buffalo (CUBRC) Large-Energy National Shock (LENS) Tunnel (low-to-moderate enthalpy reacting $\mathrm{CO}_{2}$ environments, transition onset and turbulent heating), and the Graduate Aeronautical Laboratories of the California Institute of Technology (GALCIT) T5 Hypervelocity Shock Tunnel (moderate to high-enthalpy reacting $\mathrm{CO}_{2}$ environments, and turbulent heating). 
The test detailed herein was performed in perfect-gas $\mathrm{N}_{2}$ in the Arnold Engineering Development Center (AEDC) Tunnel 9. Data were obtained across a very wide range of Reynolds numbers in order to evaluate the accuracy of CFD tools at predicting turbulent flows in an environment free from the chemical non-equilibrium effects present in the CUBRC LENS and GALCIT T5 tests. In addition to the AEDC Tunnel 9 test, a small amount of data was also obtained in the LaRC 20-Inch Mach 6 Air Tunnel using the same wind tunnel model for comparison to the AEDC results. These two tests are expected to complete the heat-shield aeroheating test program.

\section{Experimental Method}

\section{A. Facility Descriptions}

\section{AEDC Tunnel 9 Description}

The Air Force's Arnold Engineering Development Center Tunnel 9, located in Silver Spring, Maryland, is a hypersonic, nitrogen-gas, blow-down wind tunnel with interchangeable nozzles that allow for testing at Mach numbers of $7,8,10$, and 14 over a $0.054 \times 10^{6} / \mathrm{ft}$ to $48.4 \times 10^{6} / \mathrm{ft}\left(0.177 \times 10^{6} / \mathrm{m}\right.$ to $\left.158.8 \times 10^{6} / \mathrm{m}\right)$ unit Reynolds number range. A schematic drawing of the facility is shown in Figure 1 and a full description of the facility can be found in Ref. 8.

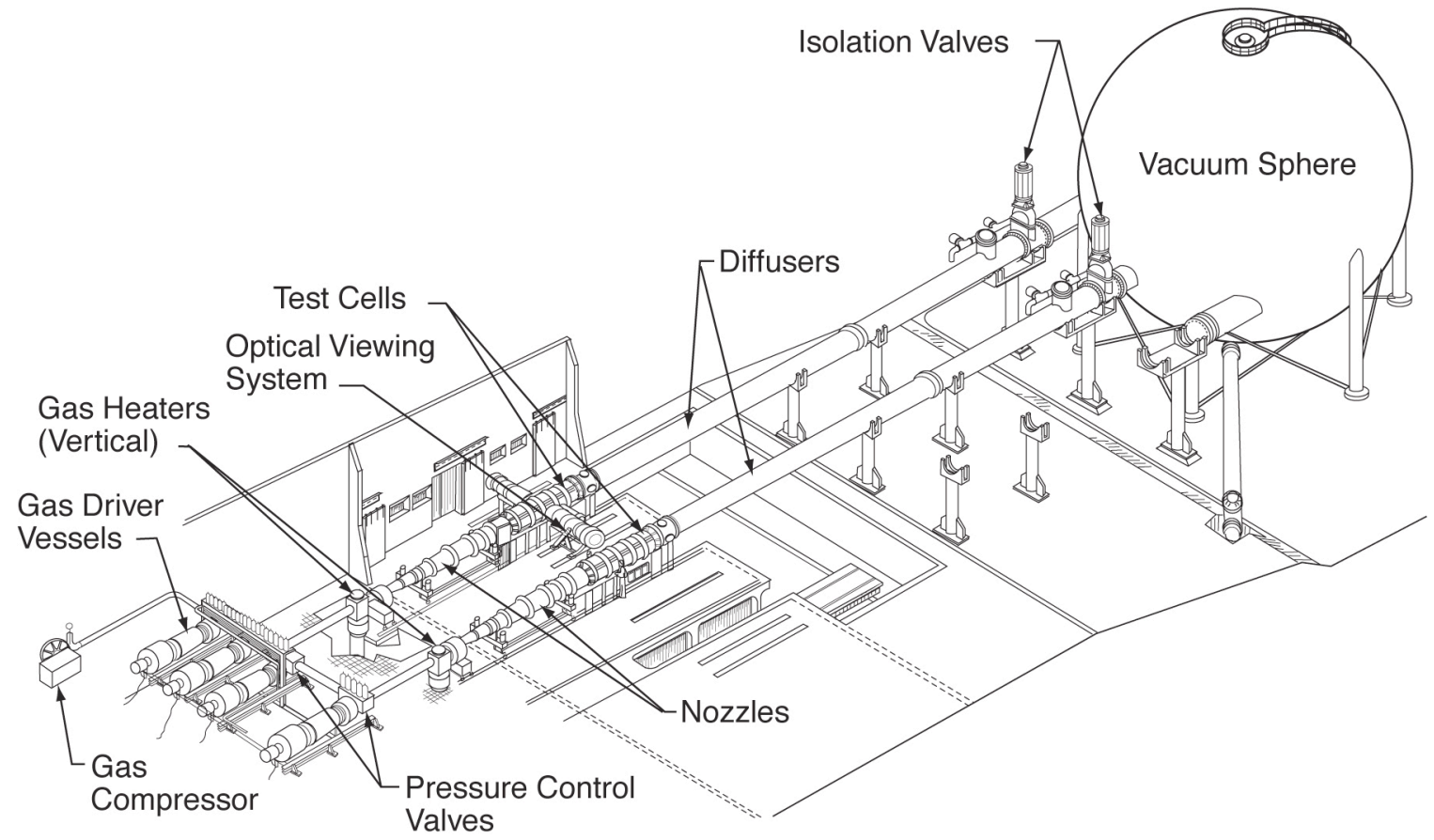

Figure 1. AEDC Tunnel 9 Schematic

The test section is a $5 \mathrm{ft}(1.52 \mathrm{~m})$ diameter, $12 \mathrm{ft}(3.66 \mathrm{~m})$ long cell that enables testing of large-scale model configurations. Tunnel 9 features a pitch system that can sweep models from -10 deg to 50 deg at pitch rates up to $80 \mathrm{deg} / \mathrm{sec}$. With the tunnel's $0.2 \mathrm{sec}$ to $15 \mathrm{sec}$ run times, the dynamic pitch capability allows for a large volume of data to be captured over an entire range of pitch angles during a single run.

During operation of the facility, the nozzle and test cell are evacuated to a pressure of less than $0.02 \mathrm{psi}(138 \mathrm{~Pa})$ and are isolated from the high-pressure side by a pair of metal diaphragms upstream of the throat. Nitrogen in the vertical gas heater is then compressed and heated to a desired pressure and temperature, where the maximum conditions are $27 \mathrm{kpsi}(186 \mathrm{MPa})$ and $3040^{\circ} \mathrm{F}(1944 \mathrm{~K})$. When the desired conditions are reached in the heater, the diaphragms are burst and the high-pressure/high-temperature nitrogen expands through the nozzle into the test cell. During the run, the driver vessels use cold gaseous nitrogen to replace the hot gas in the heater to maintain constant conditions within the test cell.

\section{LaRC 20-Inch Mach 6 Air Tunnel Description}

The NASA Langley Research Center 20-Inch Mach 6 Air Tunnel is a blow-down facility in which heated, dried, and filtered air is used as the test gas. The tunnel has a two dimensional, contoured nozzle that opens into a $0.521 \mathrm{~m}$ x $0.508 \mathrm{~m}$ (20.5 in. x 20.0 in.) test section. The tunnel is equipped with a bottom-mounted injection system that can 
transfer a model from the sheltered model box to the tunnel centerline in less than $0.5 \mathrm{sec}$. Run times of up to 15 minutes are possible in this facility, although for the current aeroheating study, run times of only a few seconds were required. The nominal reservoir conditions of this facility are stagnation pressures of 206.8 to $3447.4 \mathrm{kPa}$ (30 to 500 psia) with stagnation temperatures of 422.2 to $555.5 \mathrm{~K}\left(760^{\circ} \mathrm{R}\right.$ to $\left.1000{ }^{\circ} \mathrm{R}\right)$, which produce perfect-gas free stream flows with Mach numbers between 5.8 and 6.1 and Reynolds numbers of $1.64 \times 10^{6} / \mathrm{m}$ to $23.3 \times 10^{6} / \mathrm{m}\left(0.5 \times 10^{6} / \mathrm{ft}\right.$ to $\left.7.3 \times 10^{6} / \mathrm{ft}\right)$. A more detailed description of this facility is presented in Ref. 9 .

\section{B. Test Parametrics}

\section{AEDC Tunnel 9 Test Parametrics}

The primary focus of this study was a 22 run test performed in Tunnel 9, with 7 runs in the tunnel's Mach 10 nozzle and 15 runs in the Mach 8 nozzle. The run matrix for this test is presented in Table 2. The Mach 10 runs (3020 to 3026) spanned a free stream Reynolds number range of $1.2 \times 10^{6} / \mathrm{ft}$ to $19.1 \times 10^{6} / \mathrm{ft}$ and the Mach 8 runs spanned a range of $4.1 \times 10^{6} / \mathrm{ft}$ to $45 \times 10^{6} / \mathrm{ft}$. All Mach 10 runs were performed in continuous pitch-sweep data acquisition mode over a nominal range of 0 deg to $26 \mathrm{deg}$, although the span shrank somewhat at the higher Reynolds numbers due to shorter run times. The initial Mach 8 runs (3027 to 3030) also were performed with a continuous pitch sweep over the same range, but it was found that the duration of good flow was shorter than expected and data at the beginning and end of the runs showed signs of transient behavior. Several Mach 8 runs (3042 to 3049) were then performed at fixed angle of attack ( 0 deg or 16 deg) in order to define the period of acceptable flow quality at each condition. Additional runs (3050 to 3053) with shorter pitch-sweeps centered in the high-quality flow period were then performed to span the range of $\sim 8 \mathrm{deg}$ to $22 \mathrm{deg}$ angle of attack required by the MSL program.

In general, the Mach 10 conditions produced laminar flow except at the $14.6 \times 10^{6} / \mathrm{ft}$ condition where leeside transition was clearly evident and at the $18.5 \times 10^{6} / \mathrm{ft}$ and $19.1 \times 10^{6} / \mathrm{ft}$ conditions where turbulent leeside flow was produced. At Mach 8, laminar flow was produced at the lowest $4.1 \times 10^{6} / \mathrm{ft}$ condition, transitional flow at the $8.0 \times 10^{6} / \mathrm{ft}$ condition and turbulent flow at the higher Reynolds numbers.

Table 2. AEDC Tunnel 9 Run Matrix (nominal run-averaged conditions)

\begin{tabular}{ccccccccc}
\hline Run & $\begin{array}{c}R e_{\infty} \\
(1 / \mathrm{ft})\end{array}$ & $M_{\infty}$ & $\begin{array}{c}P_{\infty} \\
(\mathrm{Pa})\end{array}$ & $\begin{array}{c}T_{\infty} \\
(\mathrm{K})\end{array}$ & $\begin{array}{c}\rho_{\infty} \\
\left(\mathrm{kg} / \mathrm{m}^{3}\right)\end{array}$ & $\begin{array}{c}U_{\infty} \\
(\mathrm{m} / \mathrm{s})\end{array}$ & $\begin{array}{c}\Delta H \\
(\mathrm{MJ} / \mathrm{kg})\end{array}$ & $\begin{array}{c}\alpha \\
(\mathrm{deg})\end{array}$ \\
\hline 3020 & $1.85 \mathrm{E}+06$ & 9.56 & 285.1 & 58.1 & 0.0165 & 1486.3 & 0.853 & $0-26$ \\
3021 & $1.18 \mathrm{E}+06$ & 9.47 & 167.9 & 54.8 & 0.0103 & 1428.0 & 0.765 & $0-26$ \\
3022 & $4.62 \mathrm{E}+06$ & 9.80 & 656.1 & 54.4 & 0.0406 & 1474.9 & 0.832 & $0-26$ \\
3023 & $8.61 \mathrm{E}+06$ & 10.03 & 1068.3 & 51.9 & 0.0694 & 1472.5 & 0.826 & $0-26$ \\
3024 & $1.46 \mathrm{E}+07$ & 10.22 & 1696.2 & 50.2 & 0.1139 & 1475.5 & 0.829 & $0-20$ \\
3025 & $1.91 \mathrm{E}+07$ & 10.32 & 2068.1 & 48.3 & 0.1444 & 1461.8 & 0.807 & $0-18$ \\
3026 & $1.85 \mathrm{E}+07$ & 10.31 & 2079.3 & 49.5 & 0.1416 & 1479.2 & 0.833 & $5-24$ \\
3027 & $8.03 \mathrm{E}+06$ & 7.43 & 2302.3 & 74.6 & 0.1040 & 1308.8 & 0.622 & $0-26$ \\
3028 & $4.13 \mathrm{E}+06$ & 7.41 & 1162.5 & 73.5 & 0.0533 & 1294.2 & 0.602 & $0-26$ \\
3029 & $1.59 \mathrm{E}+07$ & 7.64 & 4988.8 & 80.7 & 0.2082 & 1398.3 & 0.750 & $0-26$ \\
3030 & $2.16 \mathrm{E}+07$ & 7.77 & 6158.7 & 76.6 & 0.2709 & 1386.0 & 0.728 & $0-25$ \\
3042 & $8.52 \mathrm{E}+06$ & 7.45 & 2366.9 & 73.1 & 0.1091 & 1298.6 & 0.607 & 0 \\
3043 & $1.65 \mathrm{E}+07$ & 7.65 & 4470.0 & 73.2 & 0.2059 & 1334.0 & 0.654 & 0 \\
3044 & $2.15 \mathrm{E}+07$ & 7.80 & 5407.0 & 70.4 & 0.2589 & 1333.0 & 0.650 & 0 \\
3045 & $4.50 \mathrm{E}+07$ & 7.93 & 11824.6 & 73.4 & 0.5426 & 1383.0 & 0.721 & 0 \\
3047 & $3.04 \mathrm{E}+07$ & 7.75 & 8231.8 & 73.8 & 0.3760 & 1356.4 & 0.685 & 16 \\
3048 & $4.96 \mathrm{E}+07$ & 7.98 & 11918.6 & 69.3 & 0.5792 & 1350.9 & 0.673 & 16 \\
3049 & $1.61 \mathrm{E}+07$ & 7.64 & 4968.0 & 79.8 & 0.2097 & 1391.7 & 0.739 & $8-19$ \\
3050 & $1.65 \mathrm{E}+07$ & 7.65 & 5078.3 & 79.8 & 0.2145 & 1391.8 & 0.740 & $12-22$ \\
3051 & $2.18 \mathrm{E}+07$ & 7.77 & 6235.2 & 76.6 & 0.2742 & 1386.8 & 0.729 & $8-19$ \\
3052 & $2.23 \mathrm{E}+07$ & 7.79 & 5966.0 & 73.4 & 0.2739 & 1359.1 & 0.688 & $12-22$ \\
3053 & $3.06 \mathrm{E}+07$ & 7.75 & 7989.6 & 71.9 & 0.3742 & 1339.3 & 0.660 & $9-20$ \\
\hline
\end{tabular}




\section{NASA LaRC 20-Inch Mach 6 Air Tunnel Test Parametrics}

A short test was also performed in the LaRC 20-Inch Mach 6 Air Tunnel to support the AEDC test. The primary purpose of this test was to confirm assumptions (to be detailed subsequently) made about thermal properties employed in the thermocouple data reduction process. In addition, this test also provided an opportunity to demonstrate the capability to perform continuous pitch-sweep data acquisition for heat-transfer testing with discrete gages similar to the procedure used at AEDC Tunnel 9. Runs were performed at Mach 6 over a Reynolds number range of $1.1 \times 10^{6} / \mathrm{ft}$ to $6.9 \times 10^{6} / \mathrm{ft}$; the matrix for this test is presented in Table 3 . The first 6 runs were conducted at a static angle-of-attack of $16 \mathrm{deg}$ to focus on the thermal properties questions, while the subsequent runs were performed in continuous pitch mode.

Table 3. LaRC 20-Inch Mach 6 Air Tunnel Run Matrix

\begin{tabular}{ccccccccc}
\hline Run & $\begin{array}{c}R e_{\infty} \\
(1 / \mathrm{ft})\end{array}$ & $M_{\infty}$ & $\begin{array}{c}P_{\infty} \\
(\mathrm{Pa})\end{array}$ & $\begin{array}{c}T_{\infty} \\
(\mathrm{K})\end{array}$ & $\begin{array}{c}\rho_{\infty} \\
\left(\mathrm{kg} / \mathrm{m}^{3}\right)\end{array}$ & $\begin{array}{c}U_{\infty} \\
(\mathrm{m} / \mathrm{s})\end{array}$ & $\begin{array}{c}\Delta H \\
(\mathrm{MJ} / \mathrm{kg})\end{array}$ & $\begin{array}{c}\alpha \\
(\mathrm{deg})\end{array}$ \\
\hline 1 & $6.92 \mathrm{E}+06$ & 6.04 & 1939 & 63.2 & 0.1073 & 959.1 & 0.214 & 16 \\
2 & $5.85 \mathrm{E}+06$ & 6.03 & 1633 & 62.9 & 0.0906 & 956.4 & 0.211 & 16 \\
3 & $4.02 \mathrm{E}+06$ & 6.01 & 1100 & 61.9 & 0.0620 & 945.7 & 0.200 & 16 \\
4 & $2.13 \mathrm{E}+06$ & 5.96 & 584 & 61.8 & 0.0329 & 939.4 & 0.194 & 16 \\
5 & $1.08 \mathrm{E}+06$ & 5.89 & 297 & 61.3 & 0.0169 & 924.3 & 0.179 & 16 \\
6 & $1.39 \mathrm{E}+06$ & 5.92 & 381 & 61.6 & 0.0216 & 931.4 & 0.186 & 16 \\
7 & $1.08 \mathrm{E}+06$ & 5.89 & 297 & 61.3 & 0.0169 & 924.3 & 0.179 & $0-25$ \\
8 & $2.13 \mathrm{E}+06$ & 5.96 & 584 & 61.8 & 0.0329 & 939.4 & 0.194 & $0-25$ \\
9 & $4.02 \mathrm{E}+06$ & 6.01 & 1100 & 61.9 & 0.0620 & 945.7 & 0.200 & $0-25$ \\
10 & $5.85 \mathrm{E}+06$ & 6.03 & 1633 & 62.9 & 0.0906 & 956.4 & 0.211 & $0-25$ \\
11 & $6.92 \mathrm{E}+06$ & 6.04 & 1939 & 63.2 & 0.1073 & 959.1 & 0.214 & $0-25$ \\
\hline
\end{tabular}

\section{Wind Tunnel Model Design}

A 6-inch diameter $(0.1524 \mathrm{~m})$ model of the MSL Outer Mold Line (OML)-6 configuration was fabricated from heat-treated 15-5 stainless steel (Figure 2 and Figure 3). As the flight vehicle configuration has been continuously evolving since the designs of the test model, the OML- 6 test configuration is different from the current OML-12 flight configuration. However, the differences are in the aftbody geometry, and since the primary purpose of this study was to measure forebody heating rates, these differences are not relevant.

The test model was instrumented with 39 Medtherm $^{\text {TM }}$ Type-E coaxial (chromelconstantan) thermocouples. This type of sensor is routinely used in the AEDC Tunnel 9 facility for aerothermal studies ${ }^{10}$. A schematic gage layout is shown in Figure 4. Of the gages, 33 of the 39 were located on the forebody and the remaining gages were located on the aftbody along the centerline. Of the forebody gages, 19 were evenly distributed along the centerline, with additional gages off-centerline in the windside

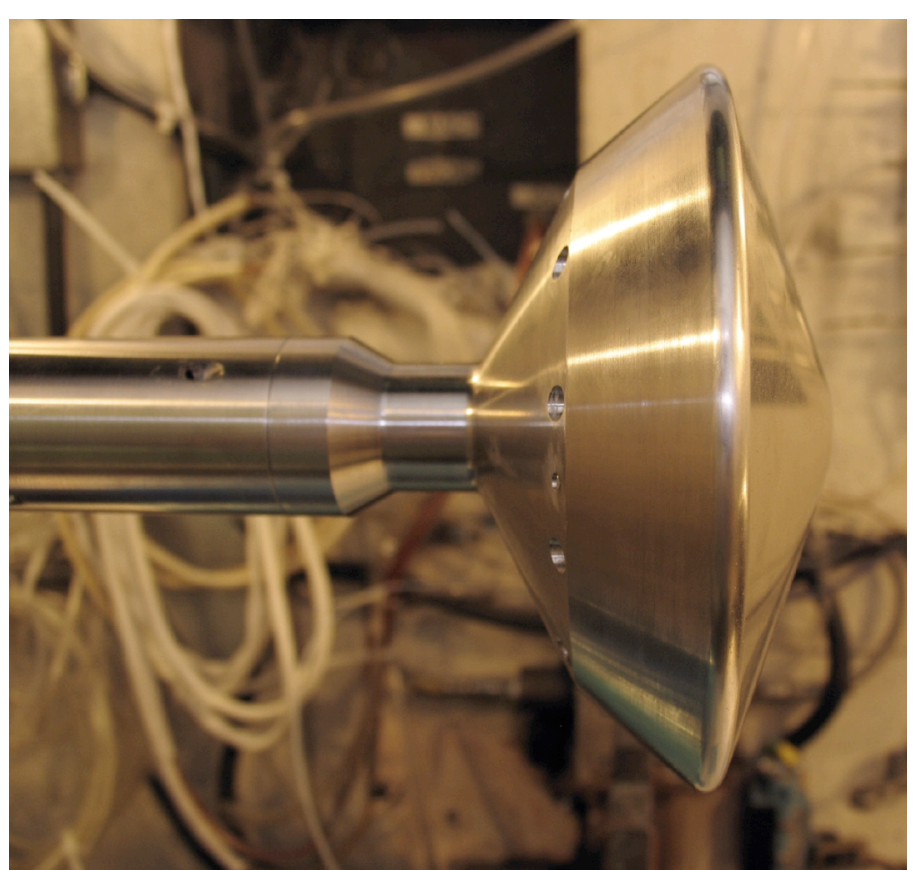

Figure 2. Close-up view of MSL model in NASA LaRC 20Inch Mach 6 Air Tunnel (retracted into model box) stagnation region and outboard on the leeside where the widest growth of the turbulent heating region occurs.

The thermocouples were fitted into the model through pre-drilled holes and fixed with Loctite ${ }^{\mathrm{TM}}$ adhesive. The thermocouples were sanded carefully to form the required chromel-constantan electrical junctions and to match the

5

American Institute of Aeronautics and Astronautics 
surface contours of the model. The shell thickness of the model (and the thermocouple length) was specified at a nominal value of 0.5 -in. (slightly less at the corners) in order to ensure that heat-conduction into the model did not violate the semi-infinite assumption (conduction does not reach the interior face) over the length of the AEDC Tunnel 9 test time, which is on the order of 1 second or less. Note that this thickness was not optimal for testing in the LaRC 20-Inch Mach 6 Air Tunnel because the model attitude control software and hardware were not designed for high-speed operation (relative to that at AEDC). Thus a pitch sweep of equivalent range ( $\sim 26 \mathrm{deg})$ to those performed in Tunnel 9 required on the order of 10 seconds, which violated the semi-infinite assumption.

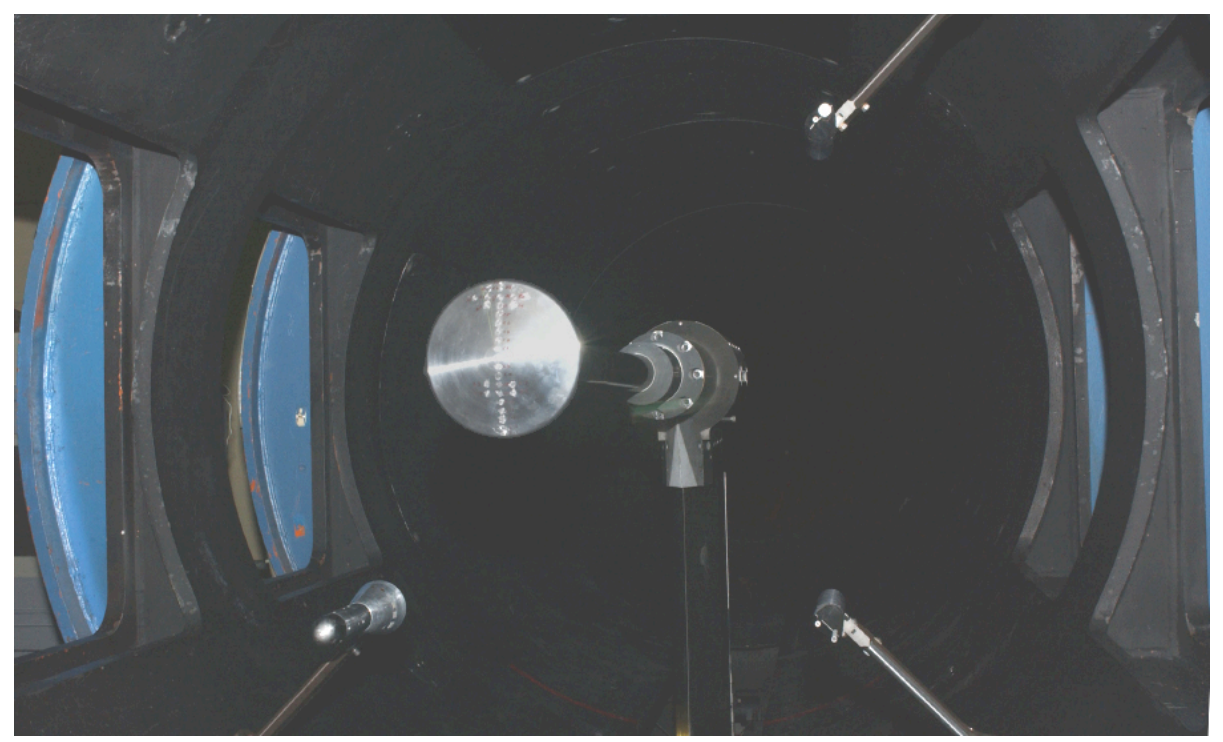

Figure 3. MSL Model installed in AEDC Tunnel 9

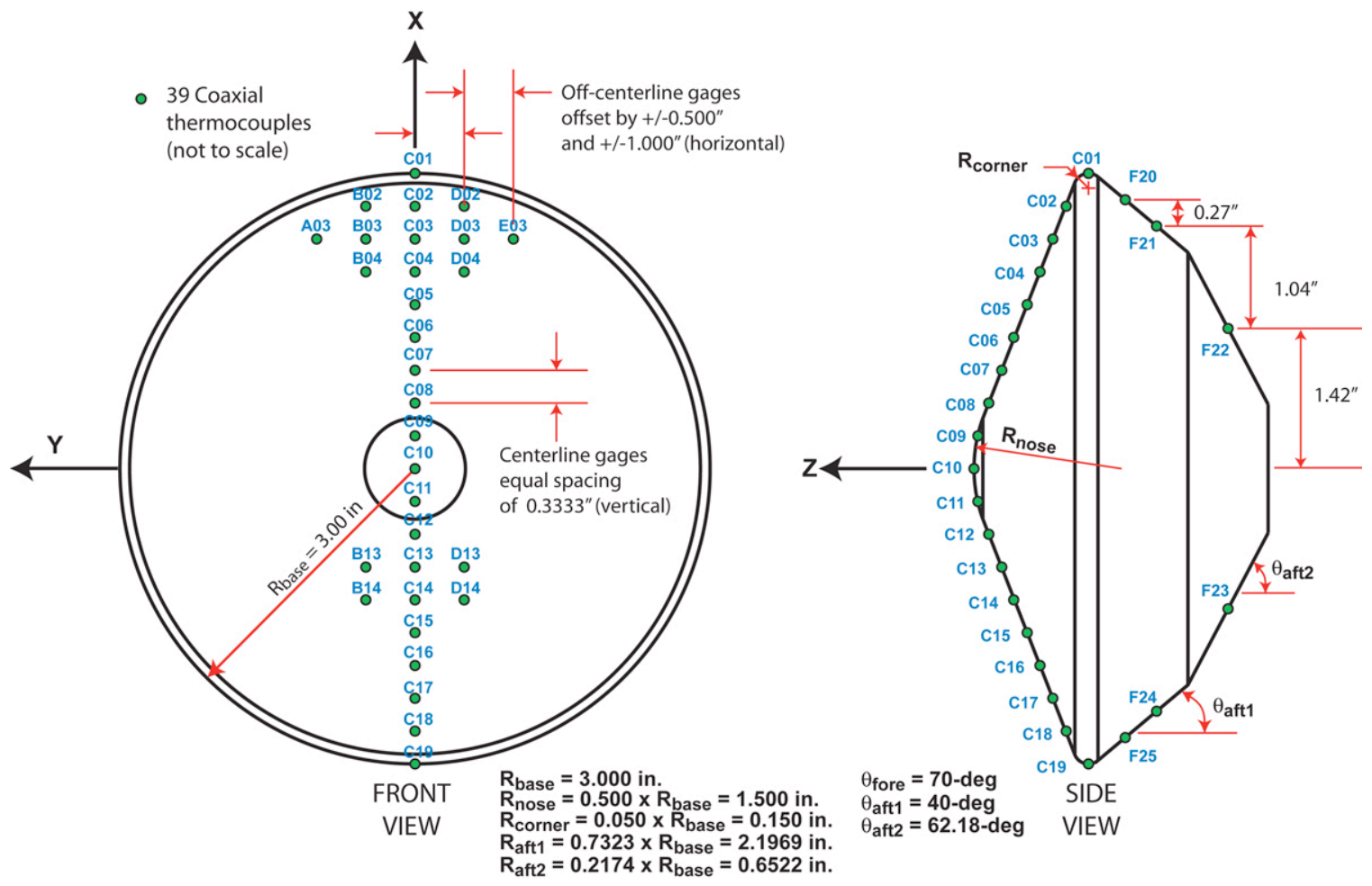

Figure 4. MSL model dimensions and thermocouple layout 


\section{Data Acquisition and Reduction}

Thermocouple voltage data from AEDC Tunnel 9 were acquired at a frequency of $500 \mathrm{~Hz}$ and analog-filtered at $30 \mathrm{~Hz}$ to eliminate $60 \mathrm{~Hz}$ analog noise (data from the LaRC 20-Inch Mach 6 Air Tunnel were acquired at $40 \mathrm{~Hz}$ ). Voltage data were converted to temperatures via the NIST standard calibration formula for Type-E thermocouples. These data were then used to compute heat-transfer rates through two-different methods: a one-dimensional conduction, semi-infinite thickness numerical integration, and a one-dimensional finite-difference numerical method. Descriptions of these methods can be found in Refs. 10-12. As a check on the data reduction process, the test data were reduced using both LaRC and AEDC software tools QCALC $^{11}$ and 1 DHEAT ${ }^{12}$. Results from the finite-difference method in either code were identical (note that the non-cartesian options in QCALC result in very slight differences from the Cartesian-only formulation in 1DHEAT). Additionally, the semi-infinite and finitedifference methods in 1DHEAT provided essentially the same results for Tunnel 9 data because the test time was short enough that the semi-infinite assumption was valid. However, the agreement was not good for data from the LaRC Mach 6 test due to the length of a run, and thus the use of the finite-difference method was required to produce valid results.

These conduction analysis methods produce a time-history of the dimensional heat-transfer rate, which is a function of both the free stream conditions and the model surface temperature. Because the free stream conditions in Tunnel 9 vary slightly over the course of the run, and because the rise in model surface temperature can be nonnegligible with respect to the stagnation temperature (which drives the convective heating) especially for the high Reynolds number Mach 8 conditions, the heat-transfer rate is not necessarily the ideal parameter with which to report the test data. Therefore, in addition to the heat-transfer rate, $q$, the product of the Stanton number times the square-root of the Reynolds number, $\operatorname{St} \times\left(\operatorname{Re}_{\infty, D}\right)^{0.5}$ is also reported herein. This quantity is defined as:

(1) $S t \times \sqrt{\operatorname{Re}_{\infty, D}}=\frac{q}{\rho_{\infty} U_{\infty} \Delta H} \sqrt{\frac{\rho_{\infty} U_{\infty} D}{\mu_{\infty}}}$

where

(2) $\Delta H=c_{p} T_{\infty}+\frac{U_{\infty}^{2}}{2}-c_{p} T_{w}$

This non-dimensional quantity is very nearly a constant over the course of the run (if the angle of attack is held fixed); the $\Delta H$ and $q$ terms balance each other as the wall temperature increases, while the $\rho_{\infty}$ and $U_{\infty}$ terms account for variations in flow conditions over the run. Also, multiplication by the square-root of the Reynolds number results in a term that has only a very slight dependence on Reynolds number (for laminar flows; for turbulent flows, an exponent of 0.2 on the Reynolds number is frequently employed). To illustrate these effects, a sample set of Tunnel 9 flow conditions are shown in Figure 5 and the heating values for a forebody gage in term of $q$ and $\operatorname{St} \times\left(\operatorname{Re}_{\infty, D}\right)^{0.5}$ are shown in Figure 6. As shown in Figure 7, $\operatorname{St} \times\left(\operatorname{Re}_{\infty, D}\right)^{0.5}$ can be used to correlate laminar heat-flux distributions over the range of test conditions, and transitional/turbulent data can clearly be identified when the values diverge from the lower Reynolds number data. It should be noted that this parameter is sometimes defined in other studies using edge conditions instead of free stream conditions for the density and velocity or the adiabatic wall enthalpy instead of the total enthalpy. 


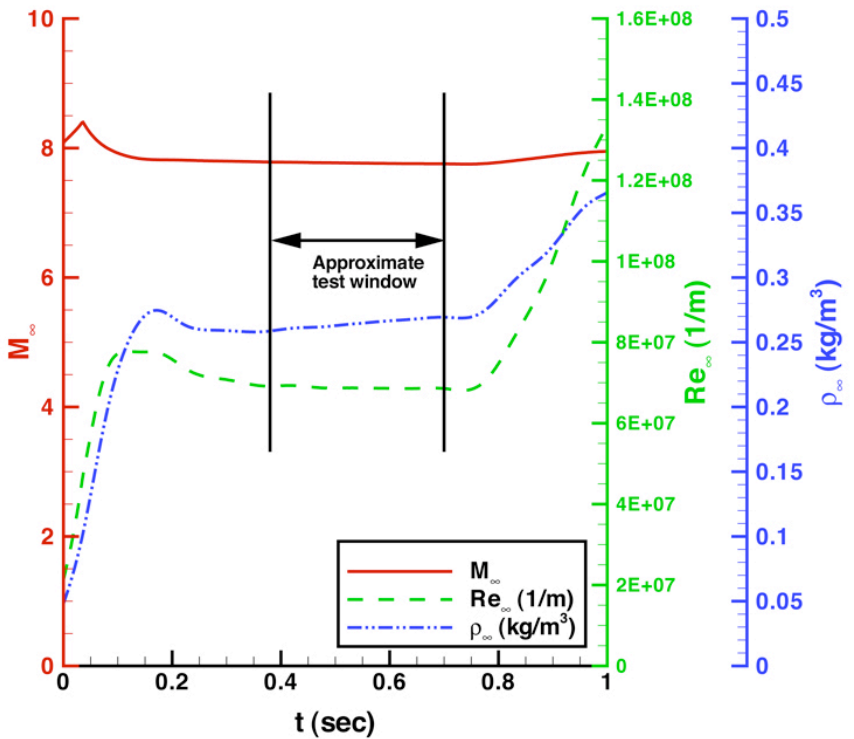

Figure 5. Sample AEDC Tunnel 9 flow conditions (Mach 8 run)

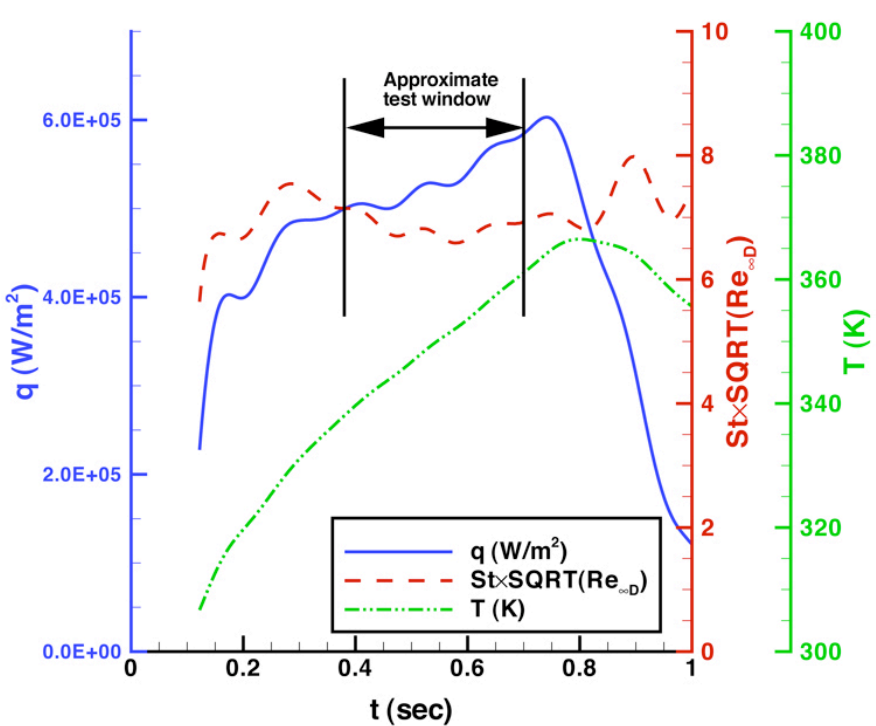

Figure 6. Sample AEDC Tunnel 9 gage temperature and heat-transfer parameters (Mach 8 run)

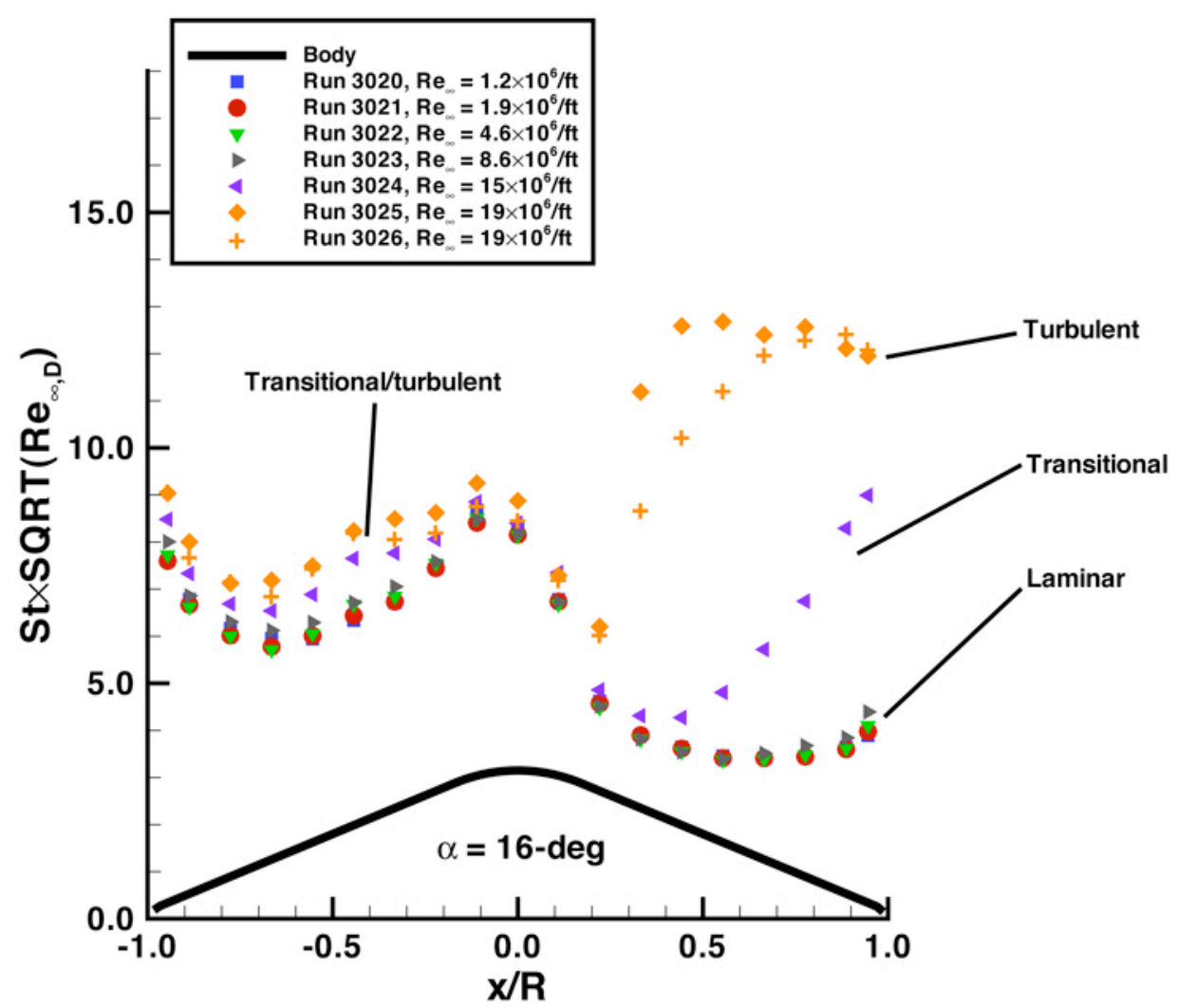

Figure 7. Correlation of centerline heating distribution vs. free stream Reynolds number

\section{E. Wind Tunnel Model Material Properties}

8

American Institute of Aeronautics and Astronautics 
The data reduction methods discussed in the previous sections require specification of the thermal properties of the wind tunnel model in order to determine heat-transfer rates from the temperature-time history. Thermal property data can be obtained from several sources (as cited in Refs. 10-12), however the accuracy of these data is hard to assess.

Prior to this test, the standard set of properties employed at AEDC Tunnel 9 for thermocouple data reduction were based on curve fits for chromel, as given by Eqs. (3)-(5). These curve fits differ from those used at NASA LaRC for chromel, as given by Eqs. (6)-(9). The thermal conductivity and specific heat fits from each equation set are plotted in Figure 8.

\section{AEDC Chromel thermal property curve fits:}

(3) $(\rho)_{m}=8719.2\left(\frac{\mathrm{kg}}{\mathrm{m}^{3}}\right)$

(4) $\left(c_{p}\right)_{m}=369.87+0.25653 \times T\left(\frac{J}{k g-K}\right)$

(5) $(k)_{m}=14.27+1.0985 \times 10^{-2} T+6.4196 \times 10^{-6} T^{2}\left(\frac{W}{m-K}\right)$

\section{LaRC Chromel thermal property curve fits:}

(6) $(\rho)_{m}=8714\left(\frac{\mathrm{kg}}{\mathrm{m}^{3}}\right)$

(7) $\left(c_{p}\right)_{m}=386.25+0.2398 \times T\left(\frac{J}{k g-K}\right)$

(8) $(k)_{m}=11.845+1.9132 \times 10^{-2} T\left(\frac{W}{m-K}\right)$

The use of chromel properties was based on the assumptions that since Type-E thermocouples are composed primarily of this material, chromel thermal properties should dictate the conduction process, and that differences in material properties between a thermocouple and the surrounding model material (15-5 stainless steel in this case) can be neglected. However, opportunities for validation of these properties have been limited, and the current test program highlighted significant differences in comparisons of CFD predictions to the tunnel data. Preliminary comparisons of the data obtained in this test program with CFD results revealed that the predictions were consistently lower than the data, sometimes by up to $20 \%$. These results were clearly outside the expected bounds of CFD reliability (a comparison to within $\pm 10 \%$ for an steady, attached, laminar, perfect-gas flow is a reasonable expectation), which cast doubt on the experimental results. After thorough investigation of many possible sources of bias and uncertainty (both experimental and computational) it was noted that the use of different material property data in the conduction analysis had a first-order effect on the resultant heat-transfer rates. The test data were then rereduced using curve fits for 17-4 stainless steel (although the model was fabricated from 15-5 stainless steel, 15-5 and 17-4 values in the literature are usually identical). Curve fits for 17-4 stainless steel used by AEDC are given in Eqs. (9)- (11) and curve fits used by NASA LaRC are given in Eqs. (12)-(14). A sample of the results produced using these different curve-fits is shown in Figure 10. Comparisons were made for all tunnel conditions, and it was found that the AEDC 17-4 stainless steel fits produced the most consistent fit with the predictions. 
AEDC 17-4 stainless steel thermal property curve fits:

(9) $(\rho)_{m}=7805.7\left(\frac{\mathrm{kg}}{\mathrm{m}^{3}}\right)$

(10) $\left(c_{p}\right)_{m}=409.76-5.3809 \times 10^{-2} \mathrm{~T}+6.0366 \times 10^{-4}\left(\frac{J}{k g-K}\right)$

(11) $(k)_{m}=11.665+1.52078 \times 10^{-2} \mathrm{~T}\left(\frac{W}{m-K}\right)$

\section{LaRC 17-4 stainless steel thermal property curve fits:}

(12) $(\rho)_{m}=7800\left(\frac{\mathrm{kg}}{\mathrm{m}^{3}}\right)$

(13) $\left(c_{p}\right)_{m}=460\left(\frac{J}{k g-K}\right)$

(14) $(k)_{m}=11.63+1.4816 \times 10^{-2} T\left(\frac{W}{m-K}\right)$

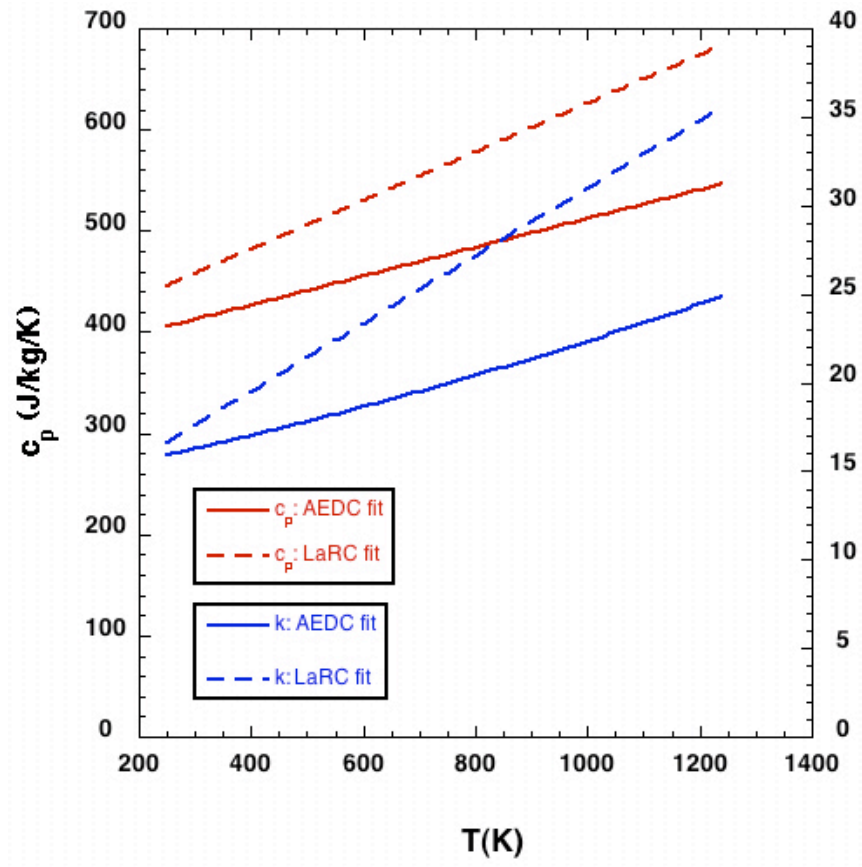

Figure 8. Chromel thermal properties

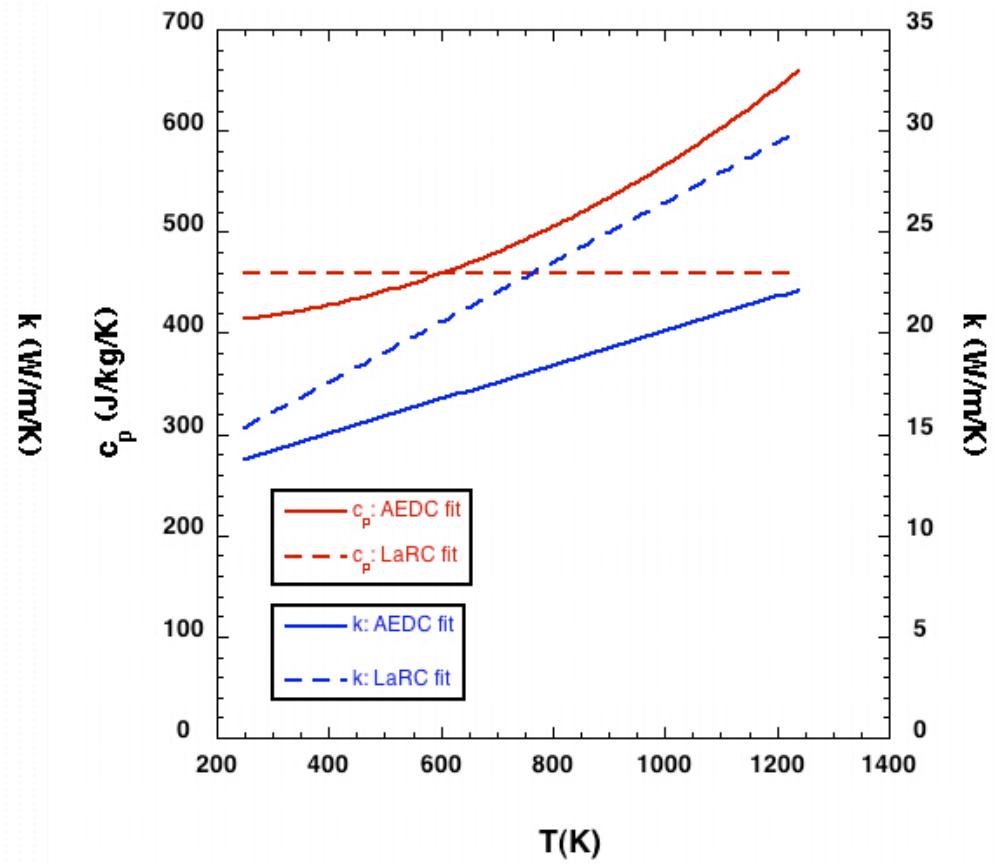

Figure 9. 17-4 stainless steel thermal properties 


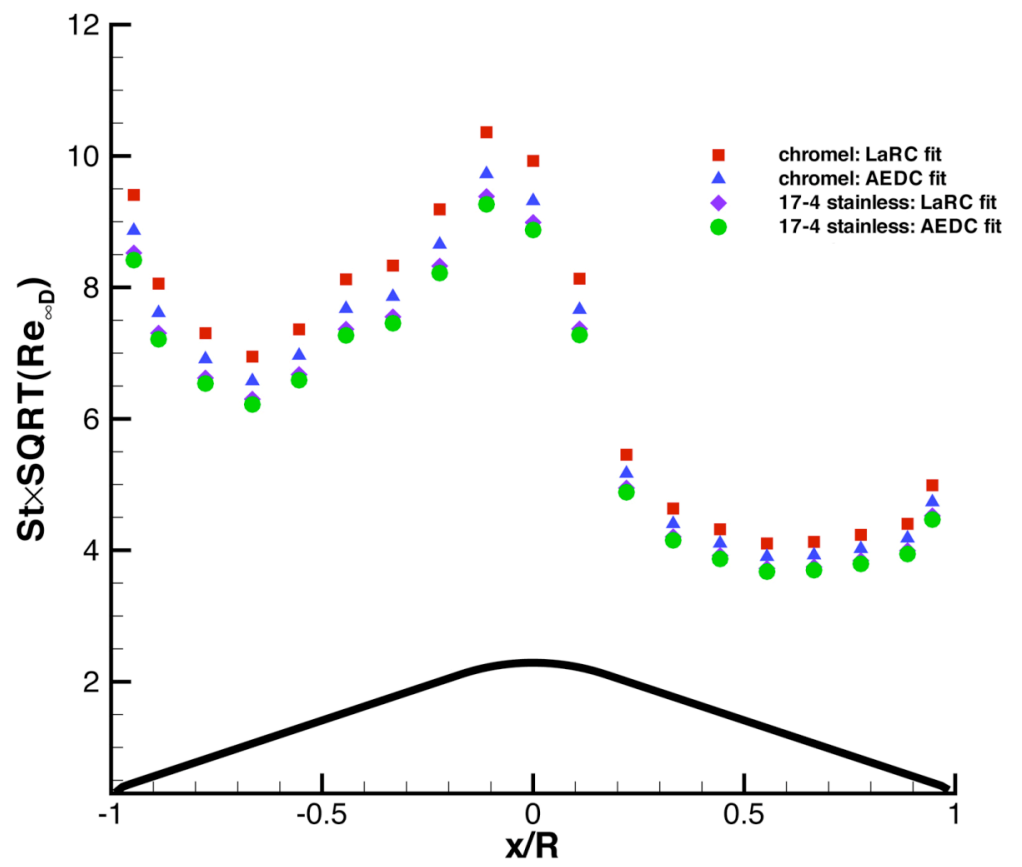

Figure 10. Variation in heating due to choice of thermal properties used in data reduction
Although good agreement with predictions was obtained when the AEDC 17-4 stainless steel properties were used to reduce the data, the purpose of this work was to obtain experimental data to validate computational methods, not the opposite. Therefore this agreement alone was not sufficient justification to employ these thermal properties curve fits.

In order to provide independent experimental validation, two additional tests were conducted: first, thermocouples installed into stainless steel and chromel plugs adjacent to NISTtraceable heat-flux calorimeters were bench-tested under a calibrated radiant lamp ${ }^{13}$. For the case of a thermocouple embedded in stainless steel, the reduced data provided the closest agreement with the calibrated source when the AEDC 17-4 stainless steel properties were used, while for the case of the thermocouple embedded in chromel, a better match was obtained when AEDC chromel properties were used. These results would seem to indicate that the thermocouple response cannot be treated independently from the material surrounding it, but rather conduction between the two materials equilibrates their behavior to that of the larger surrounding thermal mass. Note that such behavior could be much different when testing in a micro- or millisecond impulse facility in which such equilibration may not have time to occur. Another hypothesis is that the data available on chromel thermal properties is simply wrong, and the correct thermal properties are coincidently closer to those of the AEDC 17-4 stainless steel properties. AEDC has initiated a more detailed investigation into the question of material thermal properties, as discussed in Ref. 13, but this work has not yet been completed.

The second independent test was to run the MSL model designed for AEDC Tunnel 9 in the LaRC 20-Inch Mach 6 Air Tunnel in order to eliminate any possible questions about facility-specific problems. The LaRC results will be presented subsequently; but, in summary, after generating results using each of the material property curve fits, it was found that the AEDC 17-4 fits provided the best match between predictions and data, which was the same conclusion reached for the AEDC test data.

\section{F. Experimental Uncertainty}

The experimental uncertainty of the heat-transfer data is clearly very dependent on the selection of material properties. As shown in the previous sections, the uncertainty is on the order of $\pm 10 \%$ to $20 \%$. This error source could be lowered, at least in theory, through a more detailed statistically-based study of material properties. Separate from this source are uncertainties due to variations in free stream conditions, model angle of attack, and instrumentation precision. For heat-transfer testing with Type-E thermocouples on a blunt configuration such as MSL, a combined uncertainty of $\pm 6 \%$ (not including thermal properties) has been estimated. Although no formal analyses was performed for the LaRC Mach 6 tunnel because the use of thermocouples there is so rare, the flow conditions are more steady than those in Tunnel 9 due to the method of operation, so the uncertainty should be no more than that estimated for Tunnel 9. 


\section{Computational Method}

Flow field computations at the wind tunnel test conditions were performed using the LAURA code ${ }^{14,15}$. The LAURA (Langley Aerothermodynamic Upwind Relaxation Algorithm) code is a three-dimensional, finite-volume solver that includes perfect-gas, equilibrium, and non-equilibrium chemistry models. The code can be used to solve the inviscid, viscous thin-layer Navier-Stokes, or full Navier-Stokes equations. For the current study the thin-layer model was employed; it was concluded in reference 4 from computations on a similar blunt body that this model provided accurate results for attached forebody flows. Time integration to steady-state in LAURA is accomplished through a point-relaxation scheme. Roe-averaging ${ }^{16}$ with Harten's entropy fix ${ }^{17}$ and Yee's Symmetric Total Variation Diminishing limiter ${ }^{18}$ is used for inviscid fluxes, and a second-order scheme is employed for viscous fluxes. In this study, a perfect-gas model was used for the AEDC and LaRC tunnel conditions with the appropriate gas parameters for either pure $\mathrm{N}_{2}$ (AEDC Tunnel 9) or air (LaRC 20-Inch Mach 6 Air).

For the AEDC CFD cases, free stream conditions were extracted from the data set for that run at the time at which the specified angle-of-attack was reached because the free stream conditions do vary over the length of a run. For the wall boundary condition, a uniform temperature over the body equal to that recorded at the nose gage (C10) at the specified time during the run was used. For the LaRC 20-Inch Mach 6 Air Wind Tunnel cases, free stream conditions do not vary significantly over the length of the run, so the nominal conditions in Table 3 could be used. The wall temperature boundary condition was specified in the same manner as for the AEDC CFD cases.

Structured, finite-volume, multiple-block forebody grids with a singularity-free nose were employed for the computations. Grid adaptation was performed (as per the method detailed in reference 15) to align the grid with the bow shock and to produce nominal wall cell Reynolds numbers on the order of 1 .

Laminar computations were performed for AEDC and LaRC tunnel cases. Turbulent computations were performed for several cases using the algebraic Cebici-Smith turbulence model (the algebraic Baldwin-Lomax model was used for a few selected AEDC cases and found to produce only slightly different results for these perfectgas conditions). While it is recognized that more sophisticated turbulent models exist, different models can produce very different results (e.g. reference 19) and the validation status of any and all turbulence models for hypersonic flow over a given vehicle type is debatable. Algebraic models are the standard being used for MSL database development because they are computationally fast and stable, and as will be shown subsequently, the accuracy of algebraic model turbulent predictions on the forebody, at least for the conditions under consideration, is generally as good as that of the laminar predictions.

\section{Results and Analysis}

\section{A. AEDC Tunnel 9 Data}

The AEDC test was conducted in a continuous-pitch mode, and so heating data were obtained over the entire angle-of-attack range of each run ( $\sim 26 \mathrm{deg}$. at Mach 10 or $\sim 10 \mathrm{deg}$. at Mach 8$)$. This data set is far larger than can be presented herein, so for the purposes of this report, this discussion will focus on the forebody $\alpha=16$ deg data since that is the current trim-angle for flight. Values at a specific angle of attack were extracted from the data set by averaging over a time-interval encompassing $\pm 0.5 \mathrm{deg}$ from the nominal value.

A sampling of the data obtained over the complete pitch-sweep range is given in Figure 11 and Figure 12 for the Mach 10 conditions and in Figure 13 and Figure 14 for the Mach 8 conditions. Data are presented for both low and high Reynolds number runs in the Mach 8 and Mach 10 nozzles. The Mach 10 data indicate laminar behavior for all $\alpha$ at the $R e_{\infty}=1 \times 10^{6} / \mathrm{ft}$ condition and transitional or fully-turbulent turbulent behavior on the leeside $(x / R>0)$ at the

$R e_{\infty}=19 \times 10^{6} / \mathrm{ft}$ condition depending on $\alpha$. For the Mach 8 Reynolds number cases shown, the data appear to be transitional or fully-turbulent on the leeside for all $\alpha$ at both Reynolds numbers except possibly at the lowest $\alpha$ values at the $R e_{\infty}=8 \times 10^{6} / \mathrm{ft}$ condition. Additionally, the windside data at the high Reynolds number Mach 8 conditions also appear to be transitional or turbulent 


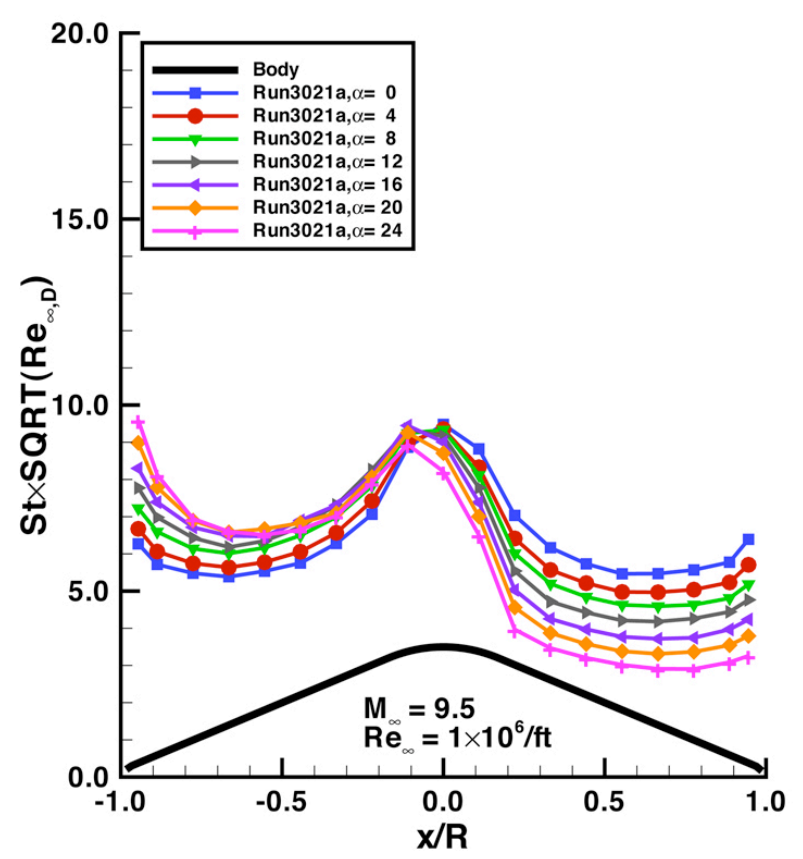

Figure 11. Angle-of-attack effects, Mach 10 nozzle, low Reynolds number

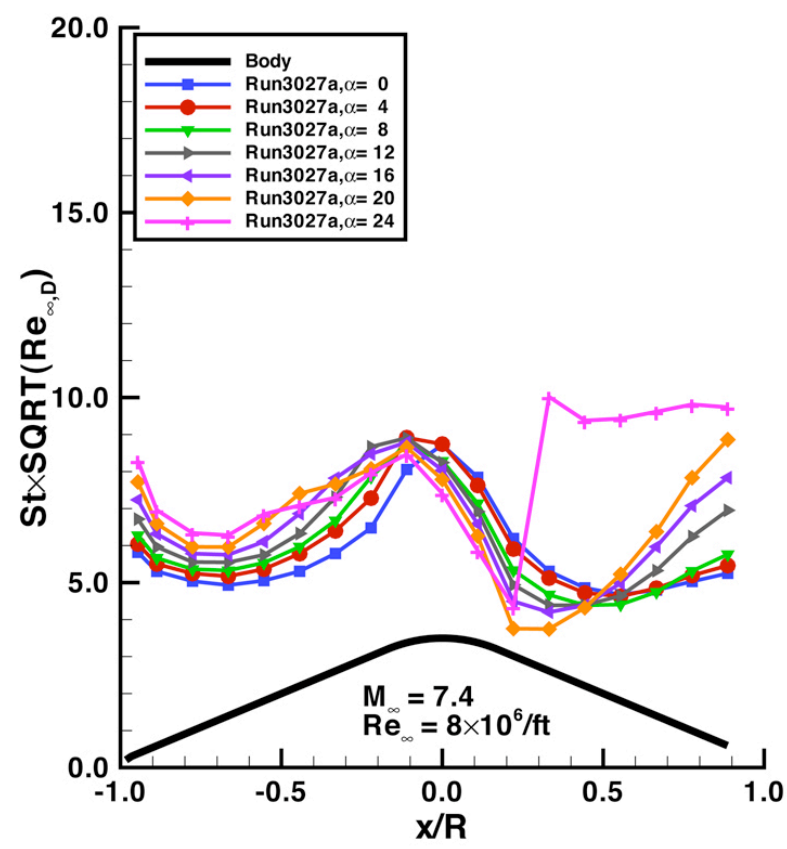

Figure 13. Angle-of-attack effects, Mach 8 nozzle, low Reynolds number

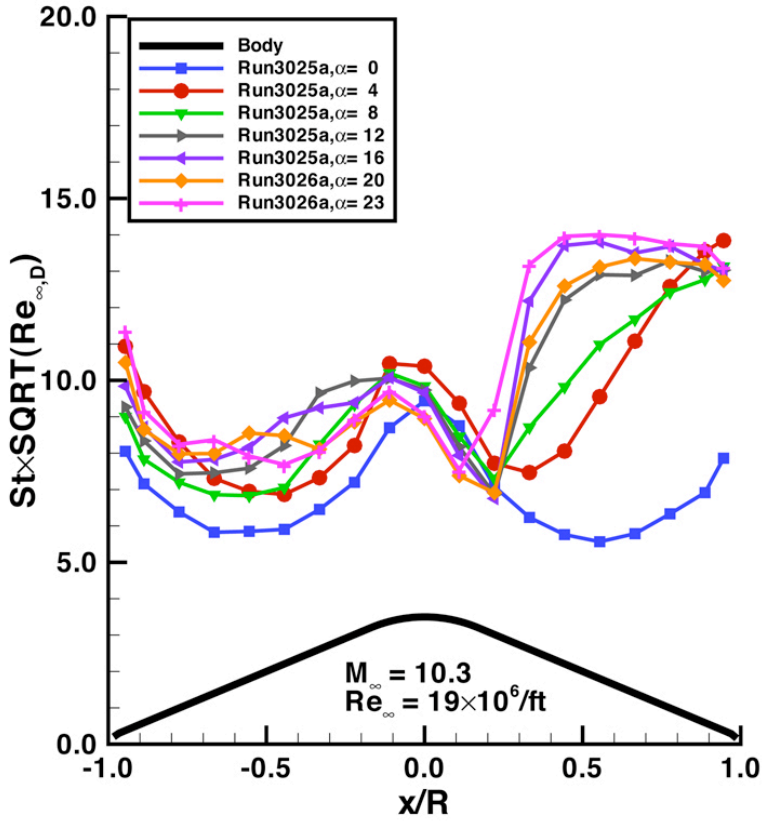

Figure 12. Angle-of-attack effects, Mach 10 nozzle, high Reynolds number

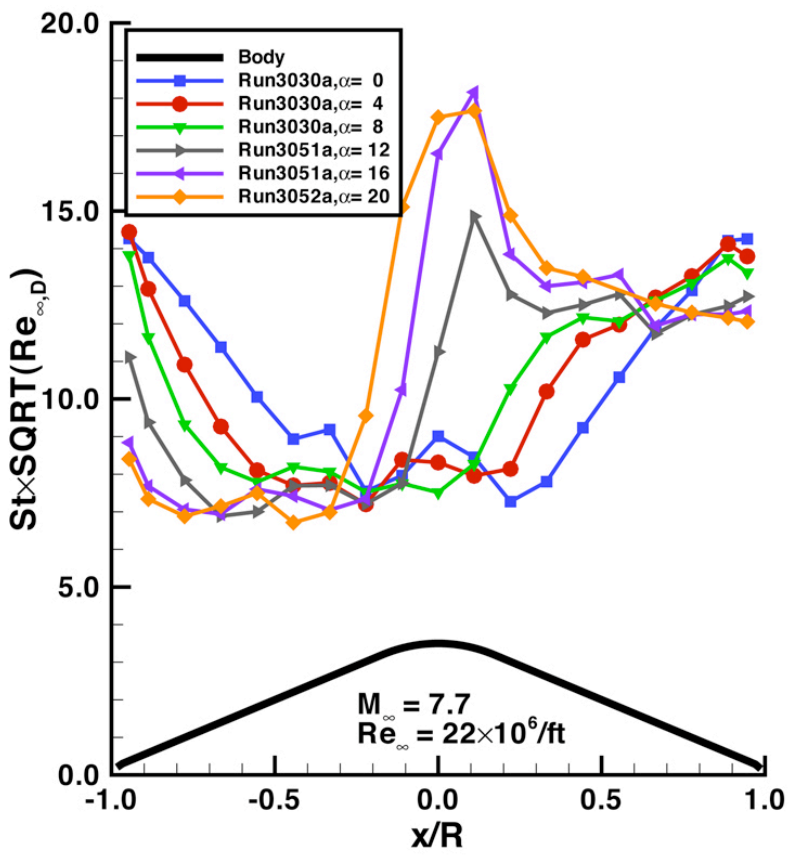

Figure 14. Angle-of-attack effects, Mach 8 nozzle, high Reynolds number

Although the purpose of this study was not to formulate or validate transition criteria, some insight into the transitional/turbulent behavior of the data can be gained by examining boundary-layer parameters such as $R e_{\theta}$ and $\operatorname{Re}_{\theta} / M_{e}$. Computed values of the parameters for $\alpha=16$ at the Mach 10 and Mach 8 nozzle conditions are plotted in Figure 15 and Figure 16. Previous studies ${ }^{7}$ have indicated that transition occurs between values of 200 to 400 for $\operatorname{Re}_{\theta} / M_{e}$, while the design specification ${ }^{3}$ for the MSL program is to assume turbulent flow in flight for values of $\operatorname{Re}_{\theta}$ 
greater than 200. Conditions in both nozzles exceed these values - by a great deal in the Mach 8 nozzle - which provides evidence that the data at higher Reynolds numbers can be interpreted as fully-turbulent.

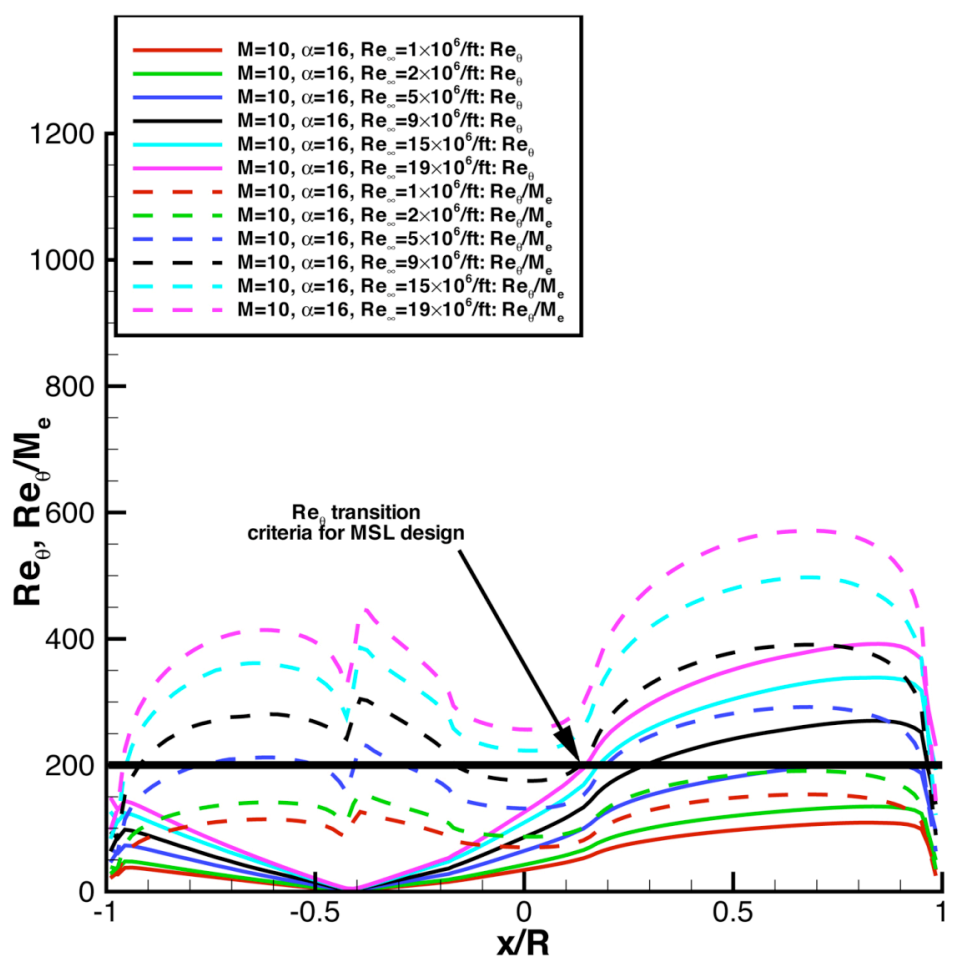

Figure 15. Boundary-layer parameters for Mach 10 nozzle conditions

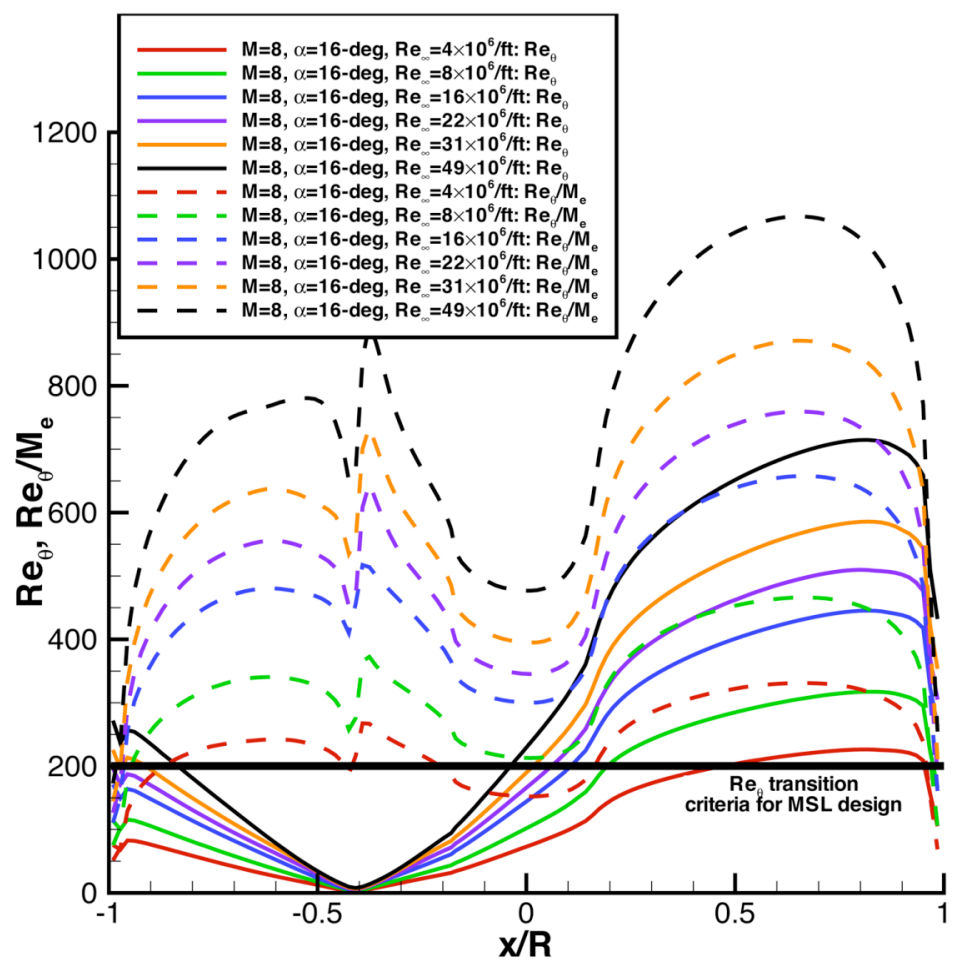

Figure 16. Boundary-layer parameters for Mach 8 nozzle conditions 
Comparisons between the tunnel data and CFD predictions along the centerline of the model are presented in Figure 17 to Figure 22 for the Mach 10 conditions and in Figure 23 to Figure 28 for the Mach 8 conditions. These results are plotted on dual ordinate axes to show both the dimensional heat flux, $q$, and the non-dimensional heating parameter, $S t \times S Q R T\left(R e_{\infty D}\right)$. In these plots the range of the ordinate axis for $q$ has been scaled so that the CFD distributions for both values overlay each other; however, because the predictions were made using a uniform wall temperature (equal to that of the nose gage), whereas the actual measured wall temperatures were not uniform, the tunnel data for $q$ and $S t \times S Q R T\left(\operatorname{Re}_{\infty D}\right)$ do not always precisely overlay each other when plotted in this manner. Error bars are also shown in these figures. These values are not meant to represent a thorough error analysis, but were simply set to $\pm 10 \%$ (which is approximately the uncertainty due to the thermal properties) to provide a fixed visual reference for evaluation of the comparisons between data and predictions.

Also note that in these figures, the turbulent predictions are for fully-developed turbulent flow over the entire forebody, whereas in the actual test, fully-developed turbulent flow was only produced over portions of the leeside of the vehicle at Mach 10 and over portions of the windside and most of the leeside at Mach 8. Although it is possible to set a transition onset location in the algebraic turbulence models used for the predictions in order to better match the observed range of boundary-layer behavior, this option was not employed in the current analysis since the transition locations were not known a priori. In theory, it would be possible to develop a transition onset criterion from the current data set, and then use that result to specify transition onset for the computational methods, but such a step was beyond the scope of the current study.

The data from the four lowest Mach 10 cases appeared to all be laminar, and for these cases the CFD and data matched to within $\pm 10 \%$ for almost all data points. The transitional data for the next-to-highest case $\left(R e_{\infty}=\right.$ $\left.15 \times 10^{6} / \mathrm{ft}\right)$ were higher than the laminar prediction, and for the leeside at the highest case $\left(R e_{\infty}=19 \times 10^{6} / \mathrm{ft}\right)$ the turbulent prediction matched the leeside centerline data. For these two cases, there were also slight indications of a non-laminar heating augmentation in the windside stagnation region such as was noted in Ref 7.

The Mach 8 comparisons are more difficult to interpret, because it is unclear whether any of the conditions provided a completely laminar case. If the two lowest Reynolds cases of $R e_{\infty}=4 \times 10^{6} / \mathrm{ft}$ and $R e_{\infty}=8 \times 10^{6} / \mathrm{ft}$ were laminar, then the differences between measurement and prediction are clearly greater than observed for the Mach 10 laminar cases, whereas if these data were transitional, the comparisons may be reasonable. For the higher Reynolds number Mach 8 cases $\left(R e_{\infty}=16 \times 10^{6} / \mathrm{ft}\right.$ to $\left.R e_{\infty}=49 \times 10^{6} / \mathrm{ft}\right)$, the $R e_{\theta} / M_{e}$ and $R e_{\theta}$ values from Figure 15 - Figure 16, as well as the shape of the experimental centerline heating distributions, clearly suggested that these data were turbulent. In fact, the two highest Reynolds number cases $\left(R e_{\infty}=31 \times 10^{6} / \mathrm{ft}\right.$ and $\left.R e_{\infty}=49 \times 10^{6} / \mathrm{ft}\right)$ appeared to be fully turbulent over the entire body, which may be the first experimental data set in which such behavior has been observed for a large-angle, blunted sphere-cone geometry such as MSL. For these four higher Reynolds number Mach 8 cases, the agreement was better than the lower Reynolds number cases, with the predictions falling within, or slightly above, the reference $\pm 10 \%$ uncertainty.

As with the Mach 10 comparisons, the Mach 8 comparisons also showed that measured heating values in the windside stagnation region exhibited a non-laminar heating augmentation that was not predicted by the computations. This result highlights a deficiency in the turbulence models used for the study. However, the methodology employed for flight heating predictions for the MSL vehicle is to perform fully-turbulent computations over the entire forebody; therefore since the augmentation observed in the data is small, it is bounded by the flight predictions and thus does not appear to be a design concern. 


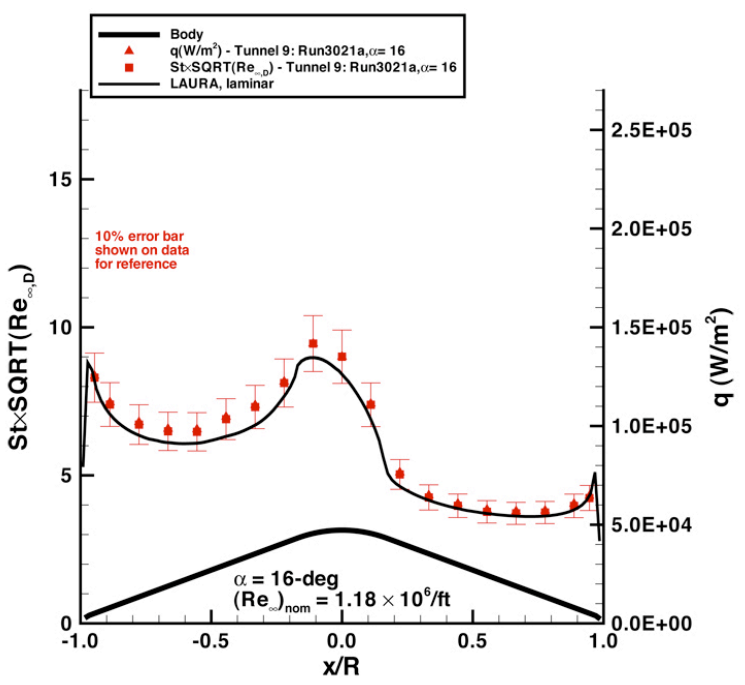

Figure 17. Comparison for $\operatorname{Mach} 10, \operatorname{Re}=1.2 \times 10^{6} / \mathrm{ft}$

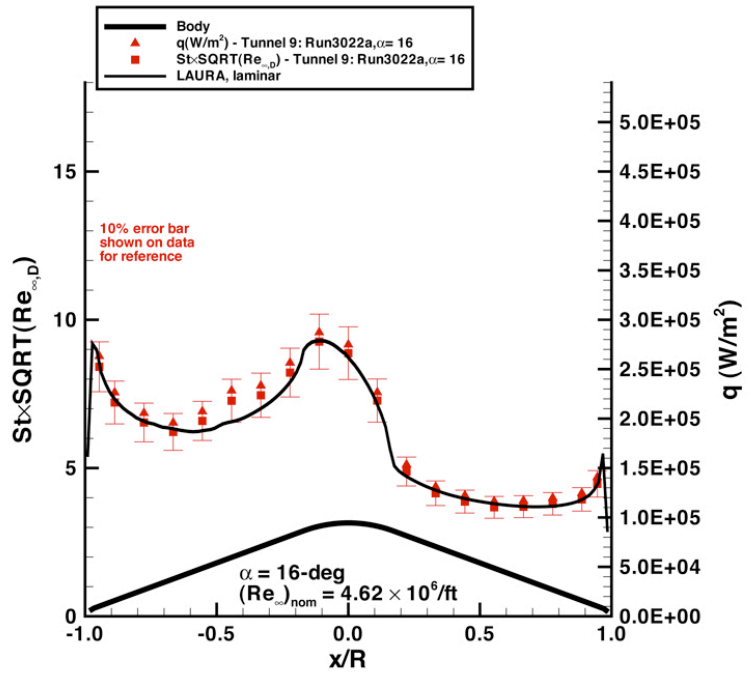

Figure 19. Comparison for Mach 10, $R e=4.6 \times 10^{6} / \mathrm{ft}$

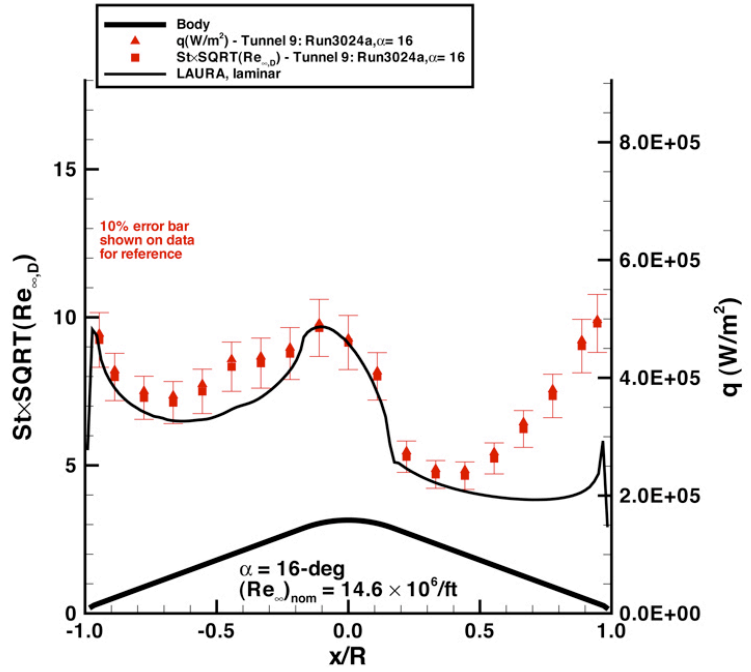

Figure 21. Comparison for Mach 10, $\mathrm{Re}=14.6 \times 10^{6} / \mathrm{ft}$

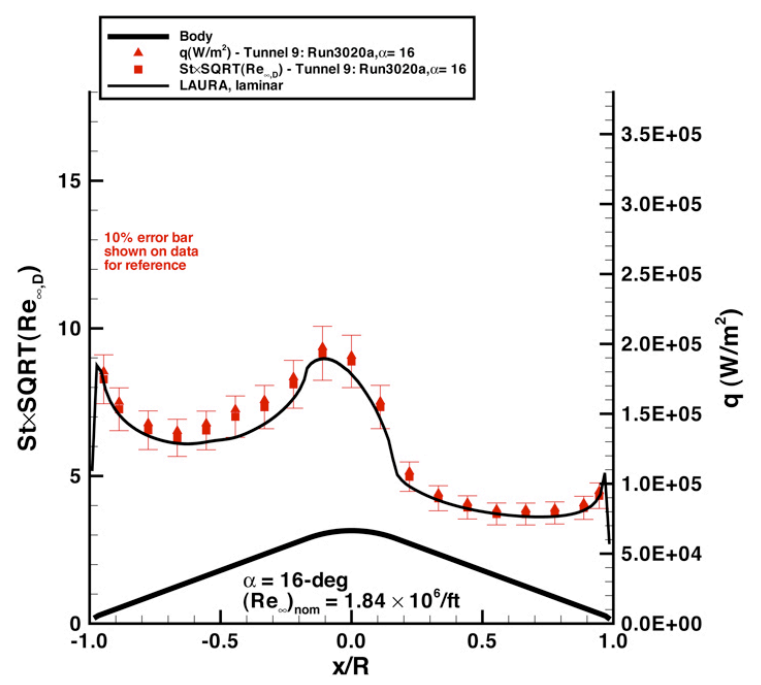

Figure 18. Comparison for Mach 10, $\operatorname{Re}=1.8 \times 10^{6} / \mathrm{ft}$

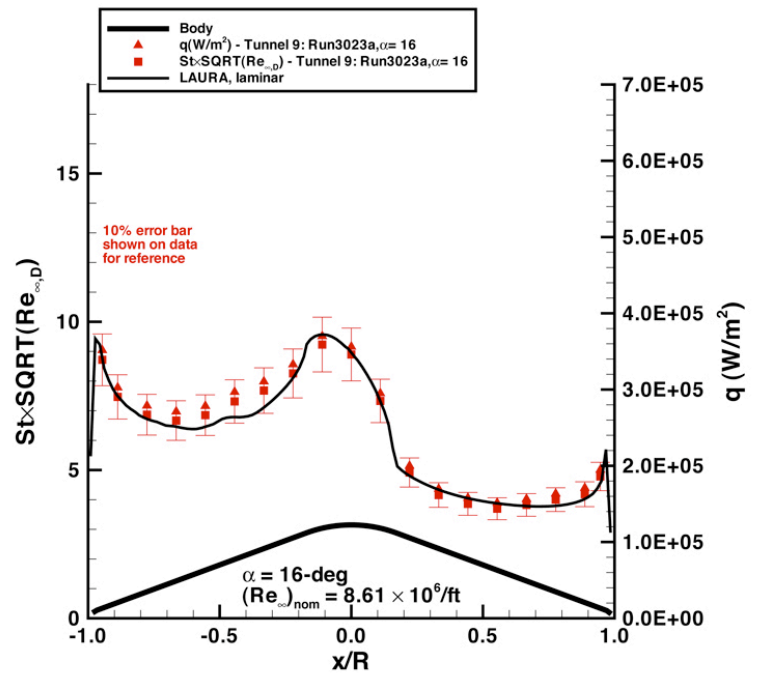

Figure 20. Comparison for Mach 10, $\operatorname{Re}=8.6 \times 10^{6} / \mathrm{ft}$

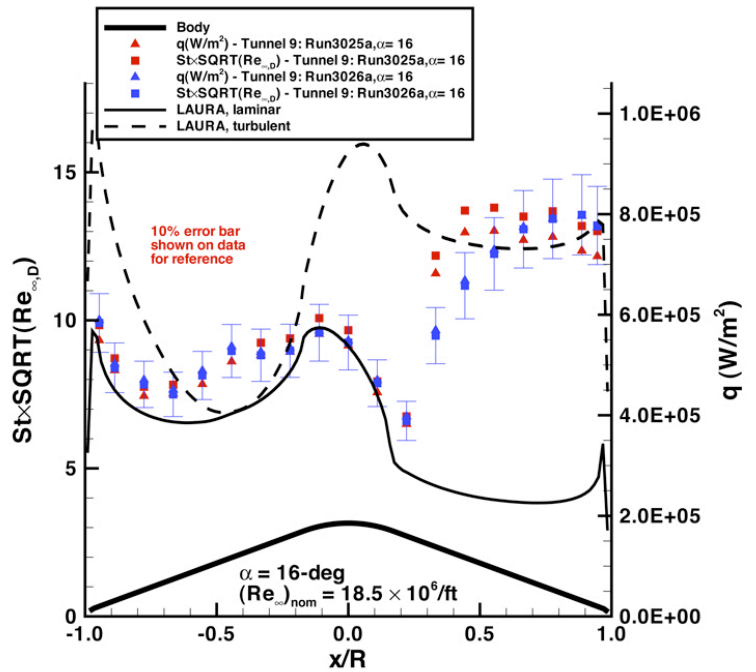

Figure 22. Comparison for Mach $10, \operatorname{Re}=18.5 \times 10^{6} / \mathrm{ft}$ 


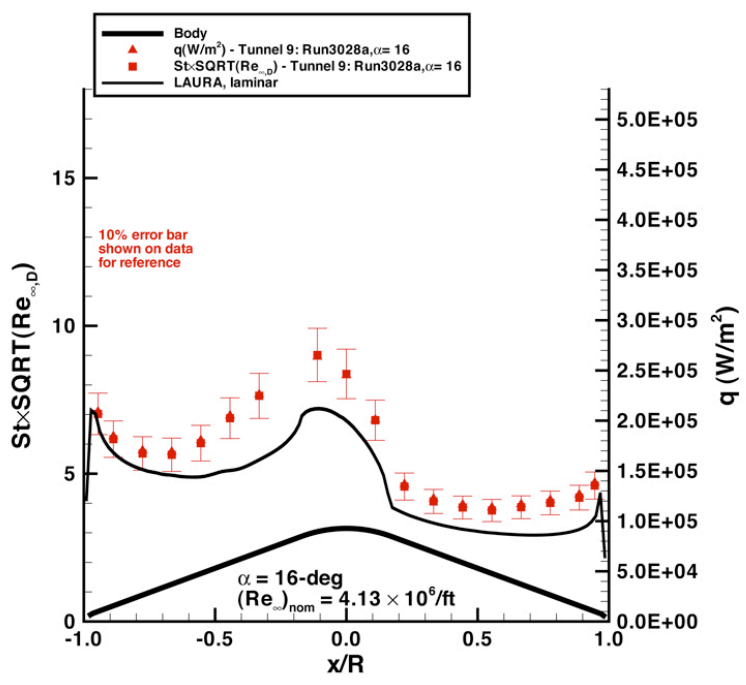

Figure 23. Comparison for Mach 8, $R e=4.1 \times 10^{6} / \mathrm{ft}$

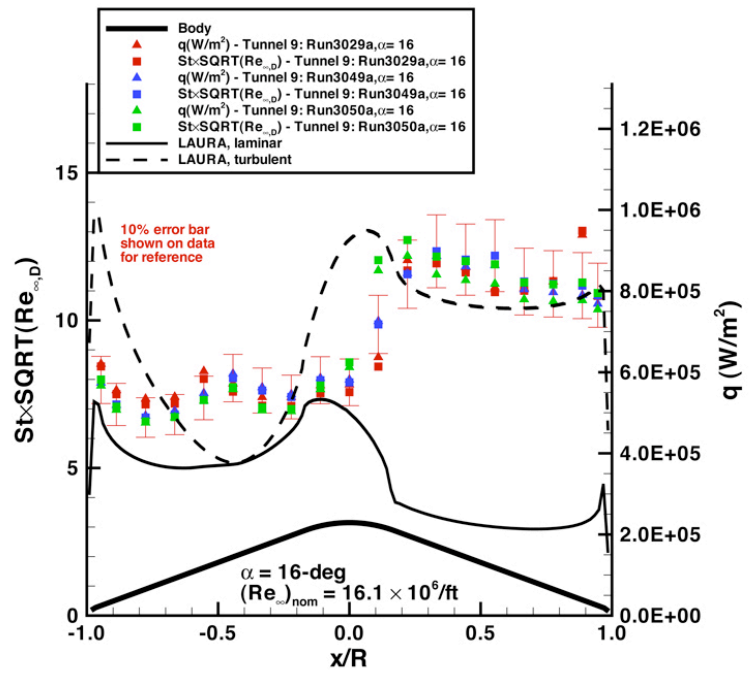

Figure 25. Comparison for Mach $8, \operatorname{Re}=16.1 \times 10^{6} / \mathrm{ft}$

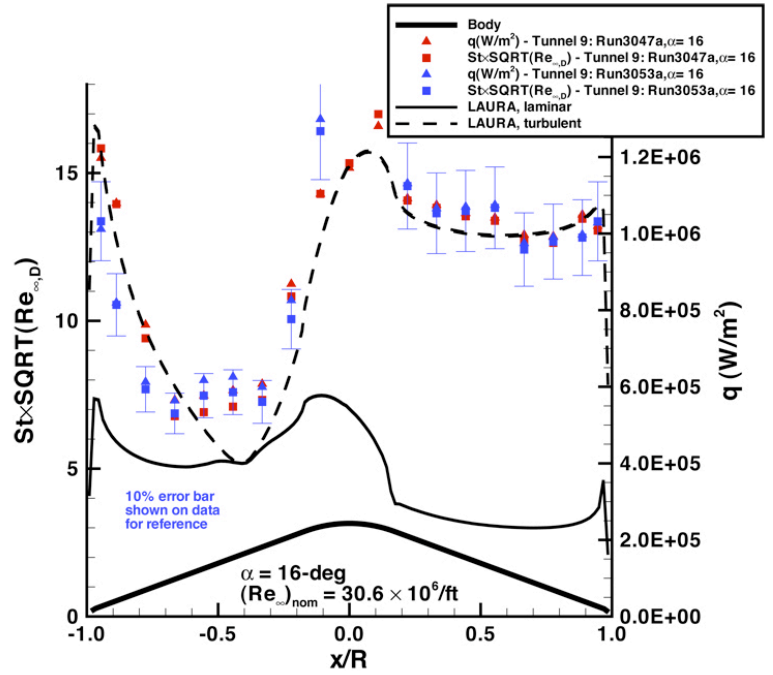

Figure 27. Comparison for Mach 8, $\operatorname{Re}=30.6 \times 10^{6} / \mathrm{ft}$

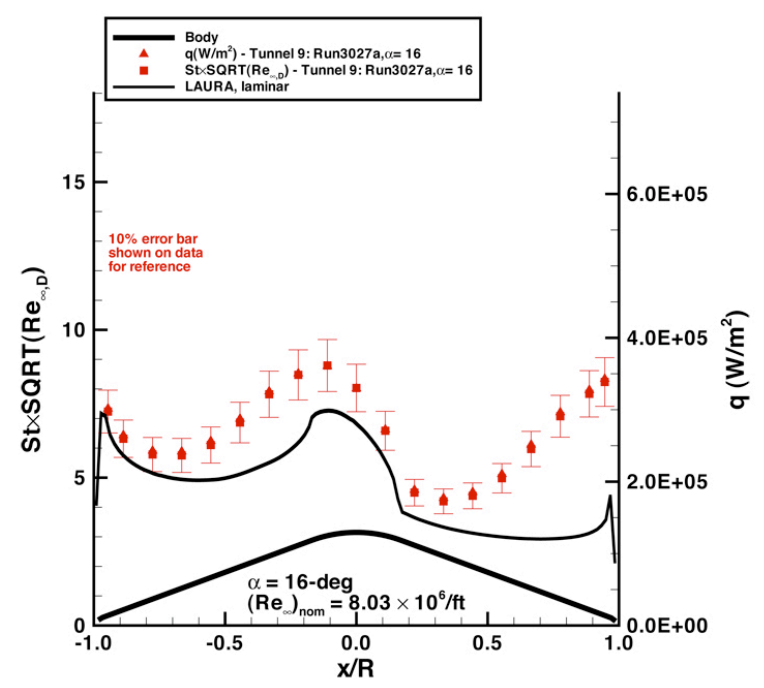

Figure 24. Comparison for $M a c h 8, R e=8.0 \times 10^{6} / \mathrm{ft}$

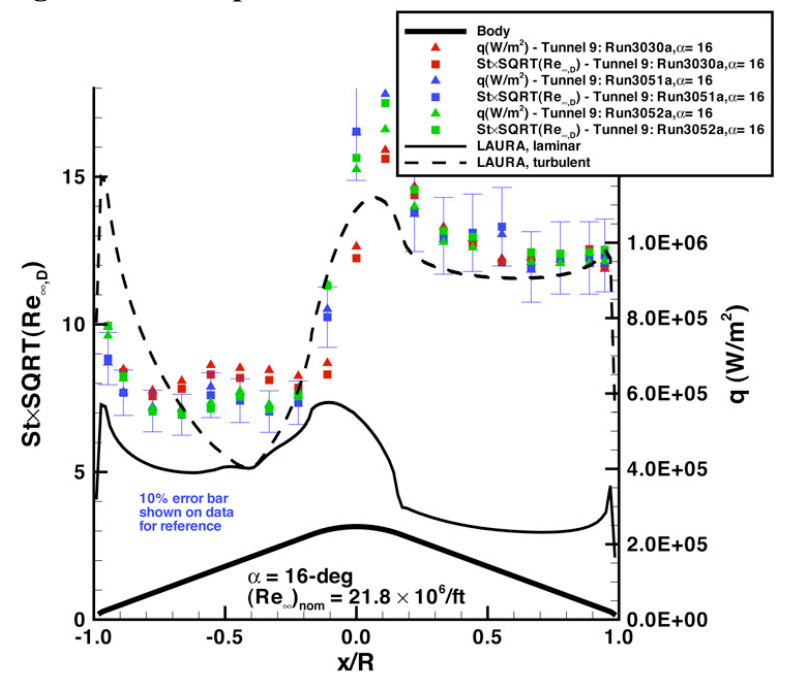

Figure 26. Comparison for Mach 8, $\operatorname{Re}=21.8 \times 10^{6} / \mathrm{ft}$

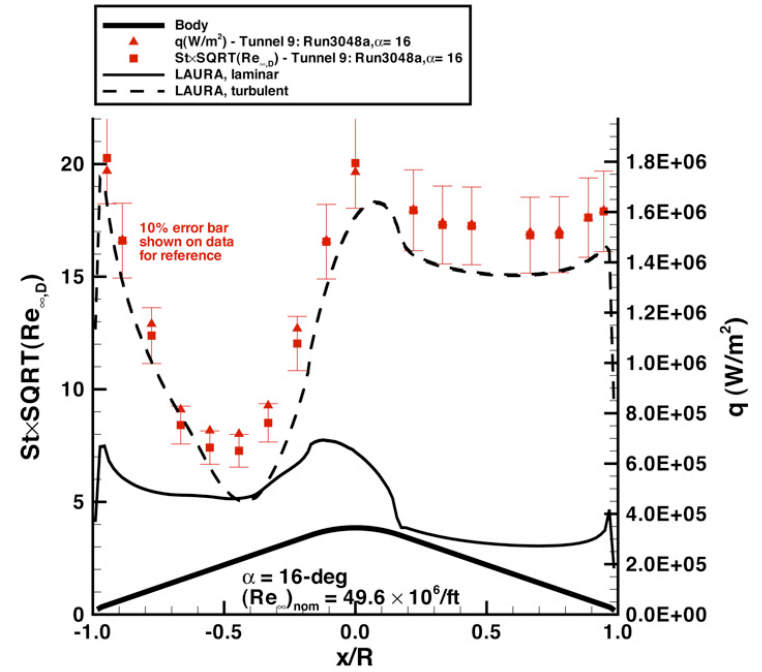

Figure 28. Comparison for Mach $8, \operatorname{Re}=49.6 \times 10^{6} / \mathrm{ft}$ 


\section{B. NASA LaRC 20-Inch Mach 6 Air Tunnel Heating Data and CFD Comparisons}

Results from the LaRC 20-Inch Mach 6 Air Tunnel test are presented in Figure 29 and Figure 30; the first figure contains the data obtained from static angle-of-attack runs, while the second figure contains data obtained from continuous pitch-sweep runs. In general, both data sets show agreement between measurements and predictions to within the reference $\pm 10 \%$ uncertainty. These data were reduced with the same thermal property curve fits used for the AEDC Tunnel 9 data, and so these results provided additional confirmation for their use.

Although the overall agreement in this test was good, it can be seen that for the continuous pitch-sweep runs the data near the corners $(\mathrm{x} / \mathrm{R} \sim+/-0.9)$ dropped well below both predictions and the data inboard of the corners. As noted earlier, the duration of a full ( 0 deg to $26 \mathrm{deg})$ pitch sweep run in the 20-Inch Mach 6 Air Tunnel is considerably longer than in AEDC Tunnel $9(\sim 10 \mathrm{sec}$ compared to $\sim 1 \mathrm{sec})$. Over the course of this longer run, the semi-infinite wall thickness assumption becomes invalid and, additionally, lateral conduction around the corner from the forebody to the aftbody causes significant energy losses. Although the semi-infinite assumption can be eliminated by using the finite-difference method (as was done here), the lateral conduction errors cannot be eliminated from a one-dimensional heat-transfer analysis. The results from this test indicate that future continuous pitch-sweep testing in the LaRC 20-Inch Mach 6 Air Tunnel would require either multiple, shorter length runs to span the entire pitch sweep range in separate segments or faster implementation of the pitch sweep.

It is also noteworthy in this data set that even at the highest test Reynolds number, only slight indications of leeside transition were observed. This behavior is in contrast to earlier tests ${ }^{7}$, at the same conditions in this facility, of 6-inch diameter phosphor-coated ceramic models of the same MSL configuration in which the transitional/turbulent augmentation of leeside heating began at lower Reynolds numbers and was of greater magnitude. This result suggests that the surface roughness of the phosphor coating plays a non-negligible role in transition onset.

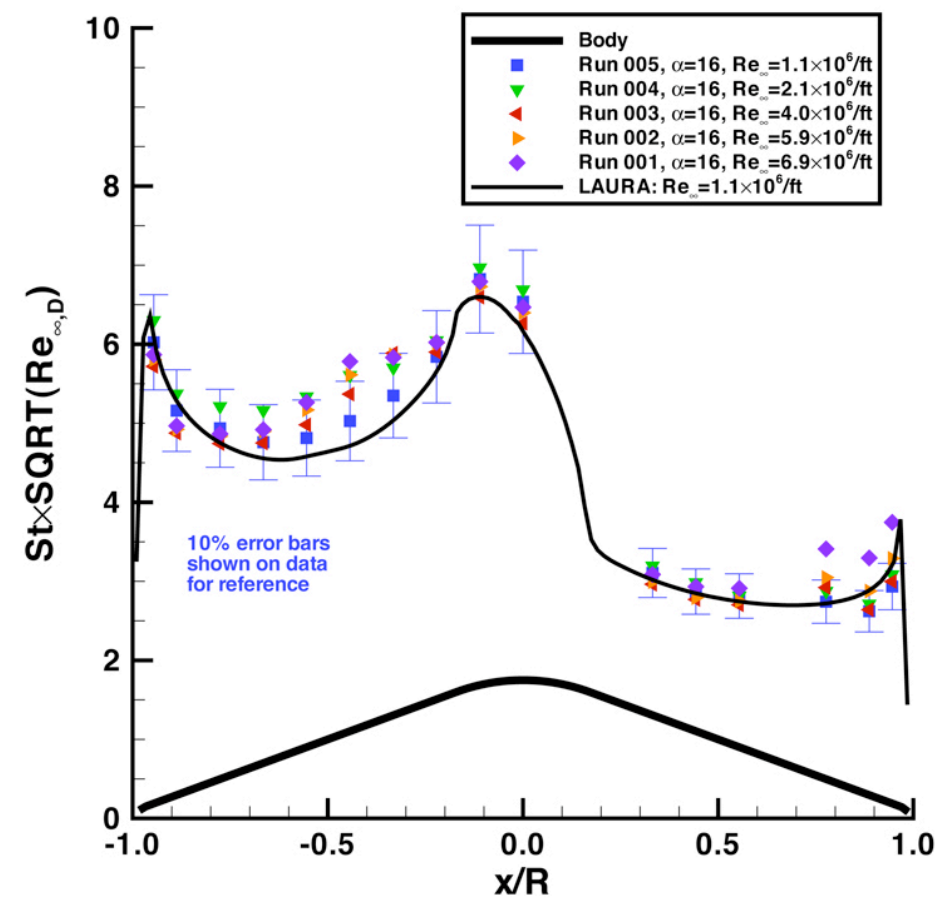

Figure 29. LaRC 20-Inch Mach 6 Air Tunnel data - static angleof-attack runs 


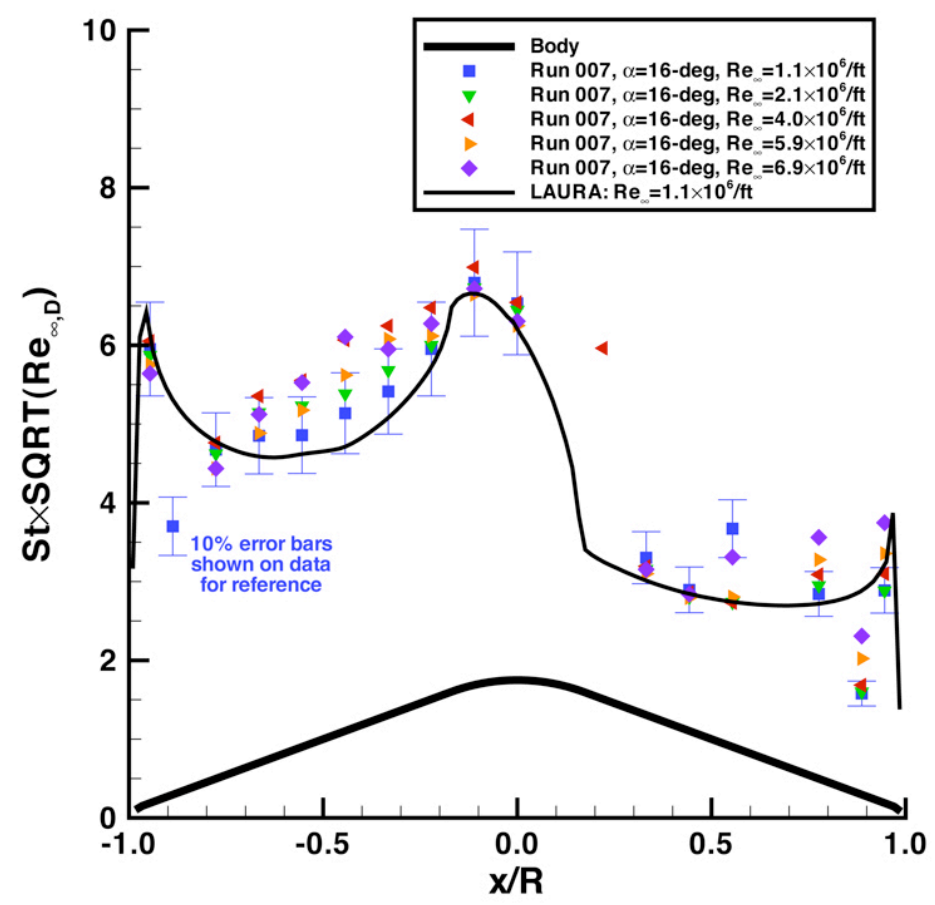

Figure 30. LaRC 20-Inch Mach 6 Air Tunnel data - continuous pitch-sweep runs

\section{Summary and Conclusions}

An experimental investigation of aerodynamic heating to the forebody of the MSL entry vehicle was conducted in the Mach 10 and Mach 8 nozzles of AEDC Tunnel 9 and laminar, transitional, and turbulent data were obtained. The purpose of this test was to determine the accuracy with which the computational tools being used in the design of the MSL vehicle could predict turbulent heating levels in an environment free from the uncertainties produced in a high-enthalpy, non-equilibrium impulse facility.

Heating data were obtained using coaxial thermocouples and comparisons were made with laminar and turbulent CFD predictions. The measurements and predictions were found to compare to within $\sim \pm 10 \%$ for cases where either fully-laminar or fully-turbulent flow was produced except at the two lowest Reynolds numbers in the Mach 8 nozzle of Tunnel 9, where it was unclear whether the data were transitional or if the comparisons revealed a bias, and in some of the higher Reynolds number Mach 8 and Mach 10 data where a non-laminar augmentation of the data was observed in the windside stagnation region.

These good comparisons were obtained only after the effects of the model material thermal properties were investigated and it was concluded that original properties used were probably incorrect. Preliminary recommendations for a new set of thermal properties for use in thermocouple data reduction were made based on these results.

To support the AEDC Tunnel 9 test, a short test was also performed in the LaRC 20-Inch Mach 6 Air Tunnel to validate the use of these thermal properties. Predictions for the Mach 6 conditions were also in good agreement with the laminar data except near the windside and leeside corners during continuous pitch-sweep operation of the tunnel. In addition to confirming the conclusions regarding thermal properties, this test also provided an opportunity to demonstrate the ability to perform heat-transfer testing in continuous pitch-sweep mode with some modifications in the current test procedure.

\section{References}

${ }^{1}$ Lockwood, M. K., "Introduction: Mars Science Laboratory: The Next Generation of Mars Landers," Journal of Spacecraft and Rockets, Vol. 43., No. 2, March-April 2006, p. 257. 
${ }^{2}$ Lockwood, M. K., Powell, R. W., Sutton, K., Prabhu, R. K., Graves, C. A., Epp, C. D., and Carman, G. L, "Entry Vehicle Configurations and Performance for the Mars Smart Lander," Journal of Spacecraft and Rockets, Vol. 43, No. 2, March-April 2006, pp. 258-269.

${ }^{3}$ Edquist, K. T. "Aerothermodynamic Environments Definition for the Mars Science Laboratory Entry Capsule," AIAA Paper 2007-1206, 45 ${ }^{\text {th }}$ AIAA Aerospace Sciences Meeting and Exhibit, Reno, NV, Jan. 8-11, 2007.

${ }^{4}$ Hollis, B. R., and Liechty, D. S., "Transition Due to Heat-Shield Cavities on a Mars Entry Vehicle," Journal of Spacecraft and Rockets, Vol. 43., No. 2, March-April 2006, pp. 354-366.

${ }^{5}$ Liechty, D. S., Hollis, B. R., and Edquist, K. T., "Mars Science Laboratory Experimental Aerothermodynamics with Effects of Cavities and Control Surfaces," Journal of Spacecraft and Rockets, Vol. 43., No. 2, March-April 2006, pp. 340-353.

${ }^{6}$ Wright, M. J., Olejniczak, J. Brown, J. L., Hornung, H. G., and Edquist, K. T., "Modeling of Shock Tunnel Aeroheating Data on the Mars Science Laboratory Aeroshell," Journal of Thermophysics and Heat Transfer, Vol. 20, No. 4, October-December 2006, pp. 641-646.

${ }^{7}$ Hollis, B. R., Liechty, D. S., Wright, M. J., Holden, M. S., Wadhams, T. P., MacLean, M. and Dyakonov, A., "Transition Onset and Turbulent Aeroheating Measurements on the Mars Science Laboratory Entry Vehicle,” AIAA Paper 2005-1437, January, 2005.

${ }^{8}$ Marren, D., and Lafferty, J., "The AEDC Hypervelocity Wind Tunnel 9," Advanced Hypersonic Test Facilities, Progress in Aeronautics and Astronautics, Vol. 198, American Institute of Aeronautics and Astronautics, Reston, VA, 2002, pp. 467-477.

${ }^{9}$ Micol, J. R. "Langley Aerothermodynamic Facilities Complex: Enhancements and Testing Capabilities," AIAA Paper 98-0147, January 1998.

${ }^{10}$ Hedlund, E. R., Hill, J. A. F., Ragsdale, W. C., and Voisinet, R. L. P., "Heat Transfer Testing in the NSWC Hypervelocity Wind Tunnel Utilizing Co-Axial Surface Thermocouples," Naval Surface Weapons Center - NSWC-MP 80-151, March 1980.

${ }^{11}$ Boyd, C. F., and Howell, A., "Numerical Investigation of One-Dimensional Heat-Flux Calculations," Naval Surface Warfare Center NSWCDD/TR-94/114, October 1994.

${ }^{12}$ Hollis, B. R., "User's Manual for the One-Dimensional Hypersonic Aero-Thermodynamic (1DHEAT) Data Reduction Code," NASA CR-4691, August 1995.

${ }^{13}$ Coblish, J. C., "Recent Aerothermal Measurement Developments Using Coaxial Thermocouples at AEDC Hypervelocity Wind Tunnel No. 9," AIAA Paper 2007-1467, 45 ${ }^{\text {th }}$ AIAA Aerospace Sciences Meeting and Exhibit, Reno, NV, Jan. 8-11, 2007.

${ }^{14}$ Gnoffo, P. A., “An Upwind-Biased, Point-Implicit Algorithm for Viscous, Compressible Perfect-Gas Flows,” NASA TP-2953, February 1990.

${ }^{15}$ Cheatwood, F. M., and Gnoffo, P. A., “User's Manual for the Langley Aerothermodynamic Upwind Relaxation Algorithm (LAURA)," NASA TM 4674, April, 1996.

${ }^{16}$ Roe, P. L., "Approximate Riemann Solvers, Parameter Vectors and Difference Schemes," Journal of Computational Physics, Vol. 43, No. 2, 1981, pp. 357-372.

${ }^{17}$ Harten, A., "High Resolution Schemes for Hyperbolic Conservation Laws," Journal of Computational Physics, Vol. 49, No. 3, 1983, pp. 357-393.

${ }^{18}$ Yee, H. C., "On Symmetric and Upwind TVD Schemes," NASA TM 88325, 1990.

${ }^{19}$ Brown, J. L., "Turbulence Model Validation for Hypersonic Flows," AIAA Paper 2002-3308, $8^{\text {th }}$ AIAA/ASME Joint Thermophysics and Heat Transfer Conference, St. Louis, MO. June 24-26, 2002. 